OPEN ACCESS

Edited by:

Marco Bacigaluppi

San Raffaele Scientific Institute (IRCCS), Italy

Reviewed by:

Hulya Karatas,

Hacettepe University, Turkey

Muge Yemisci,

Hacettepe University, Turkey

${ }^{*}$ Correspondence:

Thorsten R. Doeppner

thorsten.doeppner@med.unigoettingen.de

Specialty section:

This article was submitted to

Cellular Neuropathology,

a section of the journal

Frontiers in Cellular Neuroscience

Received: 30 June 2021

Accepted: 27 July 2021

Published: 16 August 2021

Citation:

Janssen $L$, Ai $X$, Zheng $X$, Wei $W$, Caglayan AB, Kilic E, Wang $Y$-C, Hermann DM, Venkataramani $V$, Bähr M and Doeppner TR (2021) Inhibition of Fatty Acid Synthesis Aggravates Brain Injury, Reduces

Blood-Brain Barrier Integrity and Impairs Neurological Recovery

in a Murine Stroke Model.

Front. Cell. Neurosci. 15:733973. doi: 10.3389/fncel.2021.733973

\section{Inhibition of Fatty Acid Synthesis Aggravates Brain Injury, Reduces Blood-Brain Barrier Integrity and Impairs Neurological Recovery in a Murine Stroke Model}

\author{
Lisa Janssen', Xiaoyu Ai ${ }^{1}$, Xuan Zheng', Wei Wei ${ }^{1}$, Ahmet B. Caglayan', Ertugrul Kilic ${ }^{2}$, \\ Ya-chao Wang ${ }^{3}$, Dirk M. Hermann ${ }^{4}$, Vivek Venkataramani5,6, Mathias Bähr' ${ }^{1}$ and \\ Thorsten R. Doeppner ${ }^{1,2 *}$
}

${ }^{1}$ Department of Neurology, University Medical Center Göttingen, Göttingen, Germany, ${ }^{2}$ Regenerative and Restorative Medical Research Center, Istanbul Medipol University, Istanbul, Turkey, ${ }^{3}$ The Institute of Translational Medicine, Shenzhen Second People's Hospital, The First Affiliated Hospital of Shenzhen University, Shenzhen, China, ${ }^{4}$ Department of Neurology, University of Duisburg-Essen, Essen, Germany, ${ }^{5}$ Department of Medicine II, University Hospital Frankfurt, Frankfurt, Germany, ${ }^{6}$ Institute of Pathology, University Medical Center Göttingen, Göttingen, Germany

Inhibition of fatty acid synthesis (FAS) stimulates tumor cell death and reduces angiogenesis. When SH-SY5Y cells or primary neurons are exposed to hypoxia only, inhibition of FAS yields significantly enhanced cell injury. The pathophysiology of stroke, however, is not only restricted to hypoxia but also includes reoxygenation injury. Hence, an oxygen-glucose-deprivation (OGD) model with subsequent reoxygenation in both SH-SY5Y cells and primary neurons as well as a murine stroke model were used herein in order to study the role of FAS inhibition and its underlying mechanisms. SH-SY5Y cells and cortical neurons exposed to $10 \mathrm{~h}$ of $\mathrm{OGD}$ and $24 \mathrm{~h}$ of reoxygenation displayed prominent cell death when treated with the Acetyl-CoA carboxylase inhibitor TOFA or the fatty acid synthase inhibitor cerulenin. Such FAS inhibition reduced the reduction potential of these cells, as indicated by increased $\mathrm{NADH}_{2}{ }^{+} / \mathrm{NAD}^{+}$ratios under both in vitro and in vivo stroke conditions. As observed in the OGD model, FAS inhibition also resulted in increased cell death in the stroke model. Stroke mice treated with cerulenin did not only display increased brain injury but also showed reduced neurological recovery during the observation period of 4 weeks. Interestingly, cerulenin treatment enhanced endothelial cell leakage, reduced transcellular electrical resistance (TER) of the endothelium and contributed to poststroke blood-brain barrier (BBB) breakdown. The latter was a consequence of the activated NF-кB pathway, stimulating MMP-9 and ABCB1 transporter activity on the luminal side of the endothelium. In conclusion, FAS inhibition aggravated poststroke brain injury as consequence of BBB breakdown and NF-кB-dependent inflammation.

Keywords: blood-brain barrier, cerebral ischemia, fatty acid synthesis, hypoxia, neuroprotection, reduction potential 


\section{INTRODUCTION}

After more than twenty years of intensive research activities, the pathophysiology of cerebral ischemia is still poorly understood (Nakamura and Shichita, 2019). Significant contributions have been made in the past, deciphering fundamental processes of the pathophysiology of cerebral ischemia such as excitotoxicity and inflammation (Dirnagl et al., 1999; Levine, 2004). Nevertheless, these approaches display a mechanistic and oversimplified view of the complex signaling cascade that is activated upon induction of cerebral ischemia. Such limited knowledge is therefore likely the reason why translational stroke research has failed until recently (Nakamura and Shichita, 2019). Additional experimental research beyond analyzing injurious signaling cascades of the ischemic brain and its periphery is of uttermost importance, but both adaptation and preservation mechanisms of the ischemic neuron have long been neglected. Hence, previous work by Brose et al. (2016) sought out to study whether or not fatty acids are critically involved in the adaption process of neurons exposed to in vitro hypoxia.

The synthesis of fatty acids plays a pivotal role in cell metabolism. Considering their long-chained structure, they contain vast amounts of electrons that serve as energy storage. Fatty acids represent an essential compound of cell membranes, thus forming the cell surface and stability as well as the cell compartments. Fatty acid synthesis (FAS) is conducted by two enzymes, i.e., Acetyl-CoA carboxylase and fatty acid synthase, with the former acting as the rate-limiting enzyme. After several steps of elongation, reduction and condensation, one palmitate molecule is synthesized from seven molecules of malonyl-CoA involving NADPH as a cofactor (Rassow, 2006; Heinrich et al., 2014).

In recent years, elucidating the role of fatty acids during hypoxia and/or ischemia has been brought to attention by inhibiting FAS. Experimental designs inhibiting FAS under hypoxic conditions are scarce and almost exclusively restricted to research related to oncology. In such studies, FAS is compensatorily activated in neoplastic cells that suffer from local hypoxia due to their extensive proliferation rate (Zhao et al., 2006; Svensson et al., 2016). Hence, the inhibition of FAS by cerulenin or 5-(tetradecyloxy)-2-furoic acid (TOFA) enhances apoptotic cell death in neoplastic cells to up to fifty percent (Matsumae et al., 1963; Omura, 1976; Zhao et al., 2006).

Using an in vitro stroke model on neuronal cells with up to $42 \mathrm{~h}$ of hypoxia in glucose-rich cell culture medium, Brose et al. $(2014,2016)$ analyzed the contribution of FAS on the survival of such hypoxic cells. Primary neurons and SH-SY5Y cells exposed to hypoxia displayed increased FAS, where glutamate and glutamine have been incorporated into lipids at significantly high levels (Brose et al., 2014). Inhibition of FAS in hypoxic SHSY5Y cells, on the contrary, significantly increased the cell death and revealed an elevated ratio of $\mathrm{NADH}_{2}{ }^{+} / \mathrm{NAD}^{+}$(Brose et al., 2016). The authors concluded that fatty acids may indeed serve as hydrogen acceptors upon induction of hypoxia, thus maintaining the cell reduction potential of neurons under these conditions.

Extending the research performed by Brose et al. (2014, 2016), the present work analyzed whether or not a significant role for
FAS exists in an in vitro hypoxia/reoxygenation model and under in vivo stroke conditions. The manuscript concludes with an extensive analysis of possible mechanisms being involved in FAS inhibition under stroke conditions with special emphasis on cell survival, blood-brain barrier (BBB) leakage, inflammation, and neurological recovery.

\section{MATERIALS AND METHODS}

\section{Cell Culture of Primary Neurons and SH-SY5Y Cells}

Female mice were sacrificed at 16.5 days of pregnancy via $\mathrm{CO}_{2}$ inhalation. The abdominal cavity was opened, and the embryos were removed from the uterus. After decapitation, the scalp was removed, and the skull incised in a sagittal manner. The two cortices were divided along the corpus callosum, followed by a dissection of the cerebellum and the olfactory bulb. After removal of the meninges, the cortices were transferred into ice cold PBS. For isolation of the cortex cells, the PBS was removed, and the cortices were incubated in $1 \mathrm{ml}$ of trypsin for $15 \mathrm{~min}$ at $37^{\circ} \mathrm{C}$. After $14 \mathrm{~min}$, a volume of $50 \mu \mathrm{l}$ of DNAse was added. Afterward, the mixture was centrifuged for $1 \mathrm{~min}$ at $800 \mathrm{rpm}$, the supernatant removed, $1 \mathrm{ml}$ FCS added, and the tissue was triturated by pipetting gently up and down. After further centrifugation, the cells were resuspended in neurobasal medium (Gibco, Darmstadt, Germany) with additional transferrin (SigmaAldrich, St. Louis, MO, United States), penicillin/streptomycin (PS; Gibco, Darmstadt, Germany), L-glutamine (Seromed, Dollnstein, Germany), and B27 supplement (Gibco, Darmstadt, Germany). The cells were counted and seeded at a density of 100,000 cells $/ \mathrm{cm}^{2}$. Three days after seeding, the cells were used for experiments.

SH-SY5Y cells were passaged every 3-4 days. After removal of the medium, the cells were washed with PBS and incubated for $1 \mathrm{~min}$ at $37^{\circ} \mathrm{C}$ with trypsin. For blockage of the reaction, FCS was added, and the detached cells were transferred into a tube followed by centrifugation for $5 \mathrm{~min}$ at 1,200 rpm. The cells were then washed once with PBS and centrifuged again. After resuspension of the cell pellet in neurobasal medium, they were transferred into a new cell culture flask. Given $24 \mathrm{~h}$ of resting, the cells were used for experiments.

\section{Cell Culture of Primary Endothelial Cells and bEnd.3 Cells}

Mouse brain endothelial cells (bEnd.3, CRL-2299 ${ }^{\mathrm{TM}}$, American Type Culture Collection, Manassas, Virginia, United States) were seeded in TC-plates (Sarstedt, Nuembrecht, Germany) and cultured under confluent conditions at a density of $6 \times 10^{4}$ cells $/ \mathrm{cm}^{2}$. Cells were cultured with $10 \%$ fetal bovine serumcontaining medium (Dulbecco's Modified Eagle Medium/Ham's F-12, Biochrom GmbH, Berlin, Germany).

Primary mouse brain endothelial cells were isolated according to a previously published protocol (Assmann et al., 2017). Briefly, four male C57BL/6 mice were sacrificed and whole brains were removed and stored in HBSS buffer on ice. The brain stem, 
cerebellum and meninges were removed, thereafter. The cortical tissue homogenate was pelleted by centrifugation at $1,350 \times$ $\mathrm{g}$ for $5 \mathrm{~min}$ at $4^{\circ} \mathrm{C}$, and the pellet was resuspended in $10 \mathrm{ml}$ dextran solution and vortexed extensively $(2 \mathrm{~min})$. The mixture was pelleted by centrifugation at 3,900 $\times \mathrm{g}$ for $10 \mathrm{~min}$ at $4^{\circ} \mathrm{C}$, and the pellet was resuspended in pre-warmed digestion medium and incubated at $37^{\circ} \mathrm{C}$ for $1 \mathrm{~h}$ with gentle shaking. After digestion, the microvessel fragments were pelleted by centrifugation at $1,350 \times \mathrm{g}$ for $5 \mathrm{~min}$ at room temperature and washed once in PBS. The resulting microvessel fragments were resuspended in full medium [DMEM/F12 with $20 \%$ plasma-derived serum (PDS), L-glutamine, heparin, puromycin, antibiotic/antimycotic, and endothelial cell growth supplement (ECGS)]. The endothelial cells were cultivated on $10 \mu \mathrm{g} / \mathrm{cm}^{2}$ collagen IV-coated flasks, plates or Transwell systems at $37^{\circ} \mathrm{C}$.

\section{Cell Culture of Primary Astrocytes}

Primary mouse brain astrocytes were prepared using a previously published protocol (Schildge et al., 2013). Four C57BL/6 mouse pups at postnatal day 0-2 were decapitated and whole brains were treated as described before. The meninges were dissected from the cortex hemispheres by pulling with a forceps. The pooled cortical tissue was digested with $0.25 \%$ trypsin at $37^{\circ} \mathrm{C}$ for $30 \mathrm{~min}$. The cell suspension was then centrifuged at $300 \times$ $\mathrm{g}$ for $5 \mathrm{~min}$, and the resulting pellet was suspended in $20 \mathrm{ml}$ of astrocyte full medium (DMEM supplemented with 10\% FBS and $1 \%$ penicillin/streptomycin) and cultivated on Poly-D-lysine (PDL)-coated T75 flask. The astrocytes were cultured for 1 week $\left(37^{\circ} \mathrm{C}, 5 \% \mathrm{CO}_{2}\right)$ before a full medium change to remove nonadherent cell debris. The cells were passaged with $0.25 \%$ trypsin and resuspended in full medium at a density of $6 \times 10^{4}$ cells $/ \mathrm{cm}^{2}$.

\section{Oxygen-Glucose-Deprivation (OGD) Injury}

Cells were exposed to OGD when they reached $90 \%$ confluence. For OGD, the cells were incubated in BSS0 solution $(116 \mathrm{mM}$ $\mathrm{NaCl}, 5.4 \mathrm{mM} \mathrm{KCl}, 0.8 \mathrm{mM} \mathrm{MgSO}, 1 \mathrm{mM} \mathrm{NaH} \mathrm{PO}_{4} \mathrm{H}_{2} \mathrm{O}$, $26.2 \mathrm{mM} \mathrm{NaHCO}_{3}, 10 \mathrm{mM}$ HEPES, $0.01 \mathrm{mM}$ glycine and $1.8 \mathrm{mM}$ $\mathrm{CaCl}_{2}, \mathrm{pH} 7.3$ ) and transferred to a hypoxia incubator chamber containing $0.2 \% \mathrm{O}_{2}, 5 \% \mathrm{CO}_{2}$, and $70 \%$ humidity (Toepffer Lab Systems, Göppingen, Germany). For reoxygenation after removing the BSSO solution, the cells were incubated in their proper cell culture medium for $24 \mathrm{~h}$ in the $5 \% \mathrm{CO}_{2}$ incubator at $37^{\circ} \mathrm{C}$. For cell viability assays, neuronal cells were exposed to OGD for either $10 \mathrm{~h}$ (primary neurons and SH-SY5Y cells) or for $16 \mathrm{~h}$ (bEnd.3). While using the co-culture system (see below), the experimental parameters differed with cells being exposed to OGD for $24 \mathrm{~h}$; primary endothelial cells possessed a more robust tolerance than bEnd. 3 cells in our hands.

\section{Cell Viability}

For cell viability measurement, cells were seeded in 24-well plates at a density of 200,000/well using a previously published protocol (Zhang et al., 2021). At the end of the reoxygenation period, $100 \mu \mathrm{l} \mathrm{MTT}$ solution ( $5 \mathrm{mg} / \mathrm{ml}$ dissolved in PBS) were added to each well and incubated for $3.5 \mathrm{~h}$ at $37^{\circ} \mathrm{C}$. Afterward, the supernatant was removed from each well and replaced by $500 \mu \mathrm{l}$ DMSO per well. The plates were placed on a plate shaker for $5 \mathrm{~min}$ and $100 \mu \mathrm{l}$ of each well were transferred to a microtiter plate. The analysis was performed by an absorbance microplate reader (TECAN Sunrise) at $565 \mathrm{~nm}$ absorption via the software Magellan (TECAN).

\section{In vitro Co-culture BBB Model and Transcellular Electrical Resistance (TER) Measurement}

A valid in vitro co-culture $\mathrm{BBB}$ model was used consisting of primary endothelial cells and astrocytes as described by our group before (Zhang et al., 2021). The endothelial cells were seeded on a microporous membrane in the upper compartment, whereas astrocytes were put in the bottom compartment. As such, both the luminal and the abluminal side of the $\mathrm{BBB}$ are represented. When astrocytes were grown to $90 \%$ confluence, astrocytes were passaged with $0.25 \%$ trypsin and seeded into Poly-D-lysine (PDL)-coated 24-well metal plates of the cellZscopeE instrument (nanoAnalytics, Münster, Germany). These were prepared at least 3 days before the inserts with endothelial cells were placed to the 24 -well plate. Endothelial cells grown on Collagen IV-coated inserts $(0.4 \mu \mathrm{m}$ pore diameter, translucent, Greiner Bio-One GmbH, Frickenhausen, Germany) were transferred to the cellZscopeE instrument to establish a co-culture system 2 days after isolation of the endothelial cells. Puromycin was added to the full medium during these 2 days in order to remove non-endothelial cells. After the start of the experiment, the TER values of the barrier were measured automatically under different treatment paradigms by means of impedance measurement (Eigenmann et al., 2013; Czupalla et al., 2014; Kuzmanov et al., 2016; Maherally et al., 2018). No TER measurement was performed during the OGD period itself due to technical limitations.

\section{BBB Permeability in vitro Assays With Evans Blue Albumin (EBA) and Lucifer Yellow (LY)}

The flux of different sized molecules like LY and EBA across the endothelial cell membrane of the aforementioned in vitro BBB model was analyzed as previously described (Takata et al., 2013; Zhang et al., 2021). Cell culture inserts were transferred to 24 -well plates containing an $0.8 \mathrm{ml}$ permeability assay buffer (141 mM NaCl, $2.8 \mathrm{mM} \mathrm{CaCl}_{2}, 1 \mathrm{mM} \mathrm{MgSO}_{4}, 4 \mathrm{mM} \mathrm{KCl}$, $1 \mathrm{mM} \mathrm{NaH}_{2} \mathrm{PO}_{4}, 10 \mathrm{mM}$ glucose and $10 \mathrm{mM}$ HEPES, $\mathrm{pH}$ 7.4) in the bottom (abluminal) compartment. In the inserts (luminal compartment), the culture medium was replaced by $0.2 \mathrm{ml}$ buffer containing $50 \mu \mathrm{M}$ LY (MW: $457.25 \mathrm{Da}$ ) or $4 \%$ bovine serum albumin mixed with $0.67 \mathrm{mg} / \mathrm{ml}$ EBA (MW: 67,000 Da). Samples $(200 \mu \mathrm{l})$ were collected from each bottom well at 15, 30, 45, 60 , and $120 \mathrm{~min}$ to a 96 -well plate for the next detection. After removing the samples, each well received fresh permeability assay buffer. The concentrations of LY at different time points were determined with a POLARstar Omega Multimode Plate Reader (BMG LABTECH GmbH, Ortenberg, Germany) using a fluorescein filter pair $[\operatorname{Ex}(\lambda) 485 \pm 10 \mathrm{~nm} ; \operatorname{Em}(\lambda) 530 \pm 10 \mathrm{~nm}]$. 
The EBA concentration of the abluminal chamber at different time points was measured by determining the absorbance of samples at $630 \mathrm{~nm}$ photometrically (Eigenmann et al., 2013; Takata et al., 2013; Watson et al., 2013; Maherally et al., 2018; Yang et al., 2018). The transendothelial permeability coefficient $\mathrm{P}_{\text {cells }}$ was calculated as given by Dehouck et al. (1992) and Zhang et al. (2021) with slight modifications.

\section{Quantification of Fatty Acids}

For this analysis, 6-well plates with $1 \times 10^{6}$ cells per well were applied using the Free Fatty Acid Quantification Kit (Abcam, Cambridge, United Kingdom). The cells were washed in cold PBS and scratched off. The detached cells were collected in a tube in PBS and centrifuged. Thereafter, the cells were homogenized by adding $200 \mu \mathrm{l}$ of $1 \%$ Triton X-100 in pure chloroform. The mixture was stored on ice for $30 \mathrm{~min}$ and centrifuged for 5$10 \mathrm{~min}$. The occurring lower phase was gathered in a new tube and dried at $50^{\circ} \mathrm{C}$ to eliminate the chloroform. Last traces were removed during $30 \mathrm{~min}$ in a vacuum centrifuge. By addition of the fatty acid buffer and intense vortexing, the pellet was resuspended. The standard was prepared as instructed by the manual. For the analysis, $20 \mu \mathrm{l}$ of each sample were transferred to a test plate and $30 \mu \mathrm{l}$ of assay buffer added. To each well $2 \mu \mathrm{l}$ of ACS reagent was added and incubated for $30 \mathrm{~min}$ at $37^{\circ} \mathrm{C}$. A volume of $50 \mu \mathrm{l}$ of the reaction mix was added to each well and incubated while being protected from light at $37^{\circ} \mathrm{C}$ for $30 \mathrm{~min}$. The measurement was administered in a fluorescence microplate reader at an extinction of $544 \mathrm{~nm}$ and emission of $590 \mathrm{~nm}$. The quantity of fatty acids was calculated based on the standard curve. Data are given in relation to normoxia controls, which were set as 1 .

For in vivo measurement, the animals were sacrificed on the seventh day. After preparation of the brain, the brainstem was removed and the hemispheres divided. The ischemic hemispheres (or sham hemispheres) were each washed in cold PBS and homogenized by a bead mill (TissueLyser LT, Qiagen) after addition of $200 \mu l$ 1\% Triton X-100 in pure chloroform. Further analysis was performed as explained for the cell experiments above. Data are given in relation to hemispheres from sham animals, which were set as 1 .

\section{Analysis of $\mathrm{NADH}_{2}{ }^{+} / \mathrm{NAD}^{+}$Ratio}

The $\mathrm{NADH}_{2}{ }^{+} / \mathrm{NAD}^{+}$ratio was analyzed using 6-well plates and the $\mathrm{NADH}_{2}{ }^{+} / \mathrm{NAD}^{+}$Assay Kit (fluorometric; Abcam, Cambridge, United Kingdom). After reoxygenation, the cells were washed in cold PBS, the detached cells collected in a tube and centrifuged for $5 \mathrm{~min}$ at 1,500 rpm. The supernatant was discarded, and the cell pellet resuspended in $100 \mu l$ lysis buffer. After incubation for $15 \mathrm{~min}$ at room temperature, the mixture was centrifuged again at 1,500 rpm for $5 \mathrm{~min}$, and the supernatant was used for the analysis. The standard was prepared according to the manual. On the test plate, $75 \mu \mathrm{l}$ of reaction mixture were added to every well and incubated for $1.5 \mathrm{~h}$ protected from light. The analysis was performed in a fluorescence microplate reader at ex/em $=544 / 590 \mathrm{~nm}$.

For assessment of the $\mathrm{NADH}_{2}{ }^{+} / \mathrm{NAD}^{+}$ratio in vivo, animals were sacrificed 7 days poststroke, and the brains were removed.
After dissecting the brain stem, the hemispheres were divided and washed in cold PBS. Next, the hemispheres were homogenized separately in $400 \mu l$ lysis buffer. The homogenate was centrifuged for $10 \mathrm{~min}$ at $2,500 \mathrm{rpm}$ and the supernatant transferred into a new tube. The procedures thereafter were analog to the cell experiments.

\section{Experimental Groups}

All experiments were approved by local authorities, following the ARRIVE and STAIR guidelines. Male C57BL6/J mice, obtained from Janvier Labs, were included into the experiments at the age of 8-10 weeks. The mice were housed under a circadian rhythm and were supplied with food and water ad libitum. Using a power calculation with the value of 0.8 and an effect size between 0.25 and 0.4 , mice were randomly allocated to the experimental treatment groups. All experiments were performed in a blinded fashion.

\section{Induction of Middle Cerebral Artery Occlusion (MCAO)}

After injection of buprenorphine $(0.1 \mathrm{mg} / \mathrm{kg}$ body weight $) 30 \mathrm{~min}$ prior to the start of the surgery, the animals were anesthetized by $1.5-2 \%$ isoflurane. To monitor the cerebral blood flow, a doppler probe (Perimed, Sweden) was attached to the cranium above the territory of the middle cerebral artery (MCA). By an incision at the ventral neck and division of the thymus, the common carotid artery was exposed and ligated at proximal and distal places. Another ligature knot was established at the external carotid artery. A clip was placed on the internal carotid artery, followed by an incision of the common carotid artery. Simultaneously to releasing the clip, a silicon-coated filament (Doccol, Sharon, MA, United States) was inserted into the incision toward the internal carotid artery and further to the middle cerebral artery. The filament was removed after $60 \mathrm{~min}$. Starting at the beginning of reperfusion, daily intraperitoneal injections of cerulenin (50 mg/kg body weight) dissolved in DMSO were given once on each consecutive day for the remainder of the experiment.

\section{Infarct Volumetry}

On the fourth day after induction of MCAO, the animal was sacrificed through deep anesthesia and cervical fracture. By decapitation and opening of the skull, the brain was removed. Using a brain matrix, the brain was cut into slices of $2 \mathrm{~mm}$. For staining of the vital tissue, the slices were incubated in a solution of $2 \%$ triphenyltetrazoliumchloride (TTC) in PBS for $10 \mathrm{~min}$. To measure the infarct volume, the slices were scanned and analyzed using the software ImageJ (National Institutes of Health, Bethesda, United States).

\section{Immunohistochemistry}

Immunohistochemical analyses were performed on days 7 and 28 after induction of stroke. At the time points given, the animals were perfused transcardially with $4 \%$ paraformaldehyde. The brains were cryopreserved, and coronal sections of $12 \mu \mathrm{m}$ thickness cut and stored at $-20^{\circ} \mathrm{C}$ until usage. For preparation of staining, the sections were defrosted at room temperature 
and afterward kept in ice-cold acetone. Thereafter, the slides were washed and heated in a microwave. After several washing steps, the sections were incubated with the primary antibody over night at $4^{\circ} \mathrm{C}$. The following primary antibodies were applied: polyclonal rabbit anti-Ibal (1:500, WAKO 019-19741, Osaka, Japan), polyclonal chicken anti-GFAP (1:1,000, Millipore AB 5541, Nottingham, United Kingdom), and a monoclonal mouse anti-NeuN (1:1,000; Millipore). The day after, the slides were washed, and the following secondary antibodies were applied: goat anti-chicken Alexa Fluor (1:250, 103-547-008, Immuno Jackson, Ely, United Kingdom), goat anti-mouse Alexa Fluor (1:500, Thermo Fisher Scientific), and donkey anti-rabbit Cy3 (1:250, 711-165-152 Immuno Jackson). For nuclear staining, $250 \mu \mathrm{l}$ of DAPI in TBS at a concentration of 1:10,000 were added to a last washing step and incubated for $10 \mathrm{~min}$ at room temperature.

The Terminal deoxynucleotidyl transferase (TdT)-mediated dUTP nick end labeling (TUNEL) staining was performed using the in situ cell death detection Kit, TMR red (Sigma Aldrich) on day 7. The tissue was fixated in $4 \%$ paraformaldehyde in PBS ( $\mathrm{pH} \mathrm{7.4)}$ for $20 \mathrm{~min}$ and washed afterward. To enhance the permeability, the slides were incubated in citrate buffer in a microwave. After washing, $50 \mu l$ of TUNEL reaction mixture were added to each section and incubated for $60 \mathrm{~min}$ at $37^{\circ} \mathrm{C}$ protected from light. All immunohistochemical cell count analysis was performed within the ischemic basal ganglia of the ischemic was done at $0.14 \mathrm{~mm}$ anterior, $2.5-3.25 \mathrm{~mm}$ ventral and 1.5-2.25 mm lateral from bregma.

\section{Evans Blue Extravasation}

BBB integrity was evaluated by Evans blue extravasation, which was performed as previously described (Doeppner et al., 2011; Radu and Chernoff, 2013). Briefly, $100 \mu \mathrm{l}$ of 2\% Evans Blue dye (Sigma-Aldrich, Darmstadt, Germany) was administered via the femoral vein $2 \mathrm{~h}$ before sacrifice. Subsequently, the mice were sacrificed and transcardially perfused with PBS. The ischemic hemispheres were weighed, homogenized in $2 \mathrm{~mL}$ of $50 \%$ trichloroacetic acid, and centrifuged at 10,000 rpm for $20 \mathrm{~min}$. The extracted Evans Blue dye was further diluted with ethanol, and the absorbance at $620 \mathrm{~nm}$ wavelength was measured photometrically. The Evans Blue concentration was based on a standard curve $(2.5-500 \mathrm{ng} / \mathrm{ml})$ calculated. Evans Blue extravasation of each group was evaluated, which is given as $(\mu \mathrm{g})$ Evans Blue per (g) tissue.

\section{Gelatin Zymography}

The gelatin zymography measurement was performed with affinity-support purification with (pro-)MMP-9 serving as standards as previously described (Zhang and Gottschall, 1997; $\mathrm{Hu}$ and Beeton, 2010). In short, hemispheres were lysed in a non-reducing lysis puffer containing $50 \mathrm{mM}$ Tris- $\mathrm{HCl}(\mathrm{pH} \mathrm{7.6)}$, $150 \mathrm{mM} \mathrm{NaCl}, 5 \mathrm{mM} \mathrm{CaCl} 2,0.05 \%$ BRIJ-35, 0.02\% NaN3 and $1 \%$ Triton $\mathrm{X}-100$, and afterward centrifuged at $12,000 \mathrm{rpm}$ for $5 \mathrm{~min}$. After collecting the supernatant, the protein concentration was measured (Pierce ${ }^{\text {TM }}$ BCA Protein Assay Kit, Thermo Fisher Scientific) and the samples were incubated with 1:10 volume of sepharose 4B (Sigma-Aldrich, Darmstadt, Germany) for $60 \mathrm{~min}$ at $4^{\circ} \mathrm{C}$. After incubation and centrifugation, the purified pellet was resuspended in lysis buffer containing $10 \%$ DMSO. Equal amounts of volume were then incubated with non-reducing sample buffer (Carl Roth, Karlsruhe, Germany) and loaded onto $8 \%$ polyacrylamide containing $0.1 \%$ gelatin. After electrophoresis, the gel was incubated in renaturing buffer containing 2.5\% Triton X-100 under gentle agitation for $30 \mathrm{~min}$. The gel was washed twice and incubated for $48 \mathrm{~h}$ at $37^{\circ} \mathrm{C}$ with developing buffer (Novex ${ }^{\mathrm{TM}}$ ). After incubation, the gel was stained with $0.1 \%$ Coomassie Blue for $30 \mathrm{~min}$ and then destained in washing solution containing $40 \%$ methanol and $10 \%$ acetic acid. After destaining, a white band remained behind a dark background. Thereafter, the gels were scanned and densitometrically analyzed.

\section{Western Blots}

Samples were lysed in a buffer containing $50 \mathrm{mM}$ Tris, $1 \%$ Triton$\mathrm{X} 100,131 \mathrm{mM}$ sodium chloride, $1 \mathrm{mM}$ sodium diphosphate, $1 \mathrm{mM}$ sodium fluoride, $1 \mathrm{mM}$ EDTA, $1 \%$ protease inhibitor, and $1 \%$ phosphatase inhibitor with a homogenizator for $10 \mathrm{~min}$ and subsequently centrifuged at $4^{\circ} \mathrm{C}$ with $16,000 \mathrm{rpm}$ for $10 \mathrm{~min}$. The supernatant was collected, and quantification of the protein concentration was photometrically accomplished (Pierce ${ }^{\mathrm{TM}}$ BCA Protein Assay Kit, Thermo Fisher Scientific). Reducing sample buffer (Carl Roth, Karlsruhe, Germany) was added, and the samples were heated for $5 \mathrm{~min}$ at $95^{\circ} \mathrm{C}$. Equal amounts of protein were separated on $8-12 \%$ SDS-PAGE and transferred onto nitrocellulose membranes (Bio-Rad, California, United States). Following transfer, the membranes were blocked for $1 \mathrm{~h}$ and incubated with the primary antibodies against ABCB1 (Abcam, $0.5 \mu \mathrm{g} / \mathrm{ml}$ ), NF- $\mathrm{B}$ p65 (Abcam, $0.5 \mu \mathrm{g} / \mathrm{ml}$ ), MMP-9 (Abcam, $0.5 \mu \mathrm{g} / \mathrm{ml}), \beta$-actin $(0.2 \mu \mathrm{g} / \mathrm{ml})$, and $\alpha$-tubulin $(0.1 \mu \mathrm{g} / \mathrm{ml})$ overnight. After washing with tris-buffered saline supplemented with $0.1 \%$ Tween $20^{\circledR}$ detergent (TBS-T) three times, the blots were incubated with horseradish peroxidase coupled secondary anti-mouse-antibody and anti-rabbit-antibody $(1: 10,000)$ for $1 \mathrm{~h}$. The membranes were bathed in ECL reagent and developed with the imaging system ChemiDoc ${ }^{\mathrm{TM}}$ XRS + (Bio-Rad).

\section{Measurement of Proteasome Activity}

The proteasome activity was performed as previously described (Doeppner et al., 2012). The enzyme activity was measured in left ischemic hemispheres from which homogenates were generated 7 days poststroke. The homogenates were made using a lysis buffer that contained $100 \mathrm{mM}$ Tris- $\mathrm{HCl}, 145 \mathrm{mM}$ $\mathrm{NaCl}, 10 \mathrm{mM}$ EDTA, and $0.5 \%$ Triton $\mathrm{X}-100$ at $\mathrm{pH}$ 7.5. The chymotrypsin-like activity of the proteasome was measured using Suc-LLVY-AMC (50 $\mu \mathrm{M}$; Sigma-Aldrich). The latter was incubated in a volume of $90 \mu \mathrm{l}$ of reaction buffer [50 mM Tris, $20 \mathrm{mM} \mathrm{KCl}, 1 \mathrm{mM}$ magnesium acetate, $2 \mathrm{mM}$ dithiothreitol, $1 \mathrm{mM}$ leupeptin, $1 \mu \mathrm{g} / \mathrm{ml}$ aprotinin (Sigma-Aldrich) and $1 \mathrm{mM}$ PMSF (Merck)]. Substrate cleavage was evaluated at $37^{\circ} \mathrm{C}$ in a fluorescence microtiter plate reader at $\lambda_{\text {exc. }}=355 \mathrm{~nm}$ and at $\lambda_{\text {em. }}=460 \mathrm{~nm}$. During the straight proportional phase of the enzyme kinetics between 8 and $14 \mathrm{~min}$, the delta of such a reaction was calculated. Values are given as arbitrary fluorescence 
units per min per mg protein, which was determined by means of the Bradford assay.

\section{Flow Cytometry Analysis}

Flow cytometry analysis from brain samples was performed on day 7 poststroke with slight modifications as previously described (Chu et al., 2014; Doeppner et al., 2014b, 2015). Ischemic brain hemispheres were mechanically homogenized in a buffer of collagenase type XI $(125 \mathrm{U} / \mathrm{ml})$, hyaluronidase $(60 \mathrm{U} / \mathrm{ml})$ and collagenase $(450 \mathrm{U} / \mathrm{ml})$ in $\mathrm{Ca}^{2+} / \mathrm{Mg}^{2+}$ supplemented PBS (Sigma-Aldrich). Thereafter, the samples were incubated with the antibody in question as described before (Doeppner et al., 2015). Absolute cell numbers were measured using CountBright counting beads (Invitrogen Life Sciences).

\section{Behavioral Tests}

The behavioral tests were performed as described previously (Doeppner et al., 2014a). For preconditioning, the animals were trained on two consecutive days prior to initiation of the MCAO. Afterward, the mice were tested on days 7, 14, 21, and 28 . For the rota rod test, the animal was placed on a treadmill with an accelerating velocity from 4 to $40 \mathrm{rpm}$. The time was measured until the animal dropped off with a maximum testing time of $300 \mathrm{~s}$.

To examine strength and coordination, the tight rope test was used. The mouse was brought with the front paws toward the middle of a tight rope of $60 \mathrm{~cm}$ length, and the time was measured until arrival on one of the platforms at both ends of the rope. While a healthy mouse would bring its hind paws toward the tight rope and use its tail, neurologically impaired animals are unable to do so or would even fall down. The performance was evaluated by a score ranging from $0(\mathrm{~min})$ to 20 ( $\max )$.

During the corner turn test, a mouse was placed 10 times between two boards tapering at an angel of $30^{\circ}$. The aim for the mouse was to walk toward the corner until contact to the wall with its whiskers, turning around and walking back. It was surveyed how often the mouse would turn to one side and analyzed by a formula (number left turns - number right turns/10). Animals with a neurological deficit would lateralize to the non-impaired body side, while healthy animals would show no lateralization.

In the balance beam test, fine motor skills and balance are assessed. Each animal was placed on a beam with reducing width, ending with a platform at the end of the beam. The time was measured until the platform was arrived. Out of two measurements the average was taken. For animals unable to reach the platform, a maximum time of $60 \mathrm{~s}$ was defined.

\section{Statistics}

Results are shown as means \pm SD. All data were normally distributed as indicated by the Kolmogorov-Smirnov test. Accordingly, parametric tests were applied. Statistical analysis was performed using the Student's $t$-test to compare two groups. The statistical significance of differences between several groups was assessed by a one-way analysis of variance (ANOVA) followed by the Tukey-Kramer's test for multiple comparisons. Differences were considered significant when p-values were less than 0.05 .

\section{RESULTS}

\section{Inhibition of FAS Increases Cell Death Rate in Neurons and Endothelial Cells After OGD Injury}

Brose et al. (2016) investigated the inhibition of FAS in a model of hypoxia only. The present work therefore applied an OGD model consisting of both hypoxia and reoxygenation. Neuronal cells were exposed to OGD in a glucose-free medium (BSS0) for $10 \mathrm{~h}$ followed by $24 \mathrm{~h}$ of reoxygenation under standard cell culture conditions. Both SH-SY5Y cells and primary neurons revealed significantly increased levels of fatty acids when exposed to hypoxia (Supplementary Figures 1A,B). Treatment with cerulenin, an inhibitor of the fatty acid synthase, significantly reduced fatty acid concentrations in these cells in a dose dependent manner. Likewise, incubation of cells with TOFA ( $5 \mu \mathrm{g} / \mathrm{ml})$, an inhibitor of the Acetyl-CoA carboxylase, also yielded significantly decreased concentrations of fatty acids in SH-SY5Y and primary neurons, albeit to a lesser extent. An analysis of cell death rates in SH-SY5Y cells upon induction of OGD displayed significantly increased cell injury rates. The latter was even further enhanced in the presence of either cerulenin or TOFA (Figure 1A). The results of the tumor cell line were confirmed in primary cortical neurons, i.e., both cerulenin and TOFA increased cell death after OGD when compared to the corresponding controls (Figure 1B). Of note, incubation of these cells with either cerulenin or TOFA did not yield any signs of toxicity under standard, i.e., normoxic cell culture conditions (data not shown).

Regarding clinical aspects, the integrity of the blood-brain barrier (BBB) upon stroke induction is of uttermost importance. Hence, the impact of an inhibition of the FAS in an endothelial cell line was analyzed. When bEnd. 3 cells were exposed to OGD, treatment with either cerulenin or TOFA significantly increased cell death in that endothelial cell line (Figure 1C). Again, fatty acid concentrations were increased upon induction of OGD, whereas administration of cerulenin or TOFA significantly reduced fatty acid concentrations. These data thus demonstrate the importance of fatty acids in various cell types under hypoxic conditions. Since both fatty acid concentrations and cell death rates were more affected by high concentrations of cerulenin than by TOFA, cerulenin only was used for the remainder of the study.

\section{Cerulenin Enhances BBB Leakage and Increases ABCB1 Transporter Abundance in Endothelial Cells Upon OGD Induction}

Fatty acids derive from malonyl-CoA, an inhibitor of carnitine palmityl transferase 1 , which is located at the outer mitochondrial membrane. That very location is ascribed to the antiapoptotic protein bcl-2, and a mutual activation between the two was 

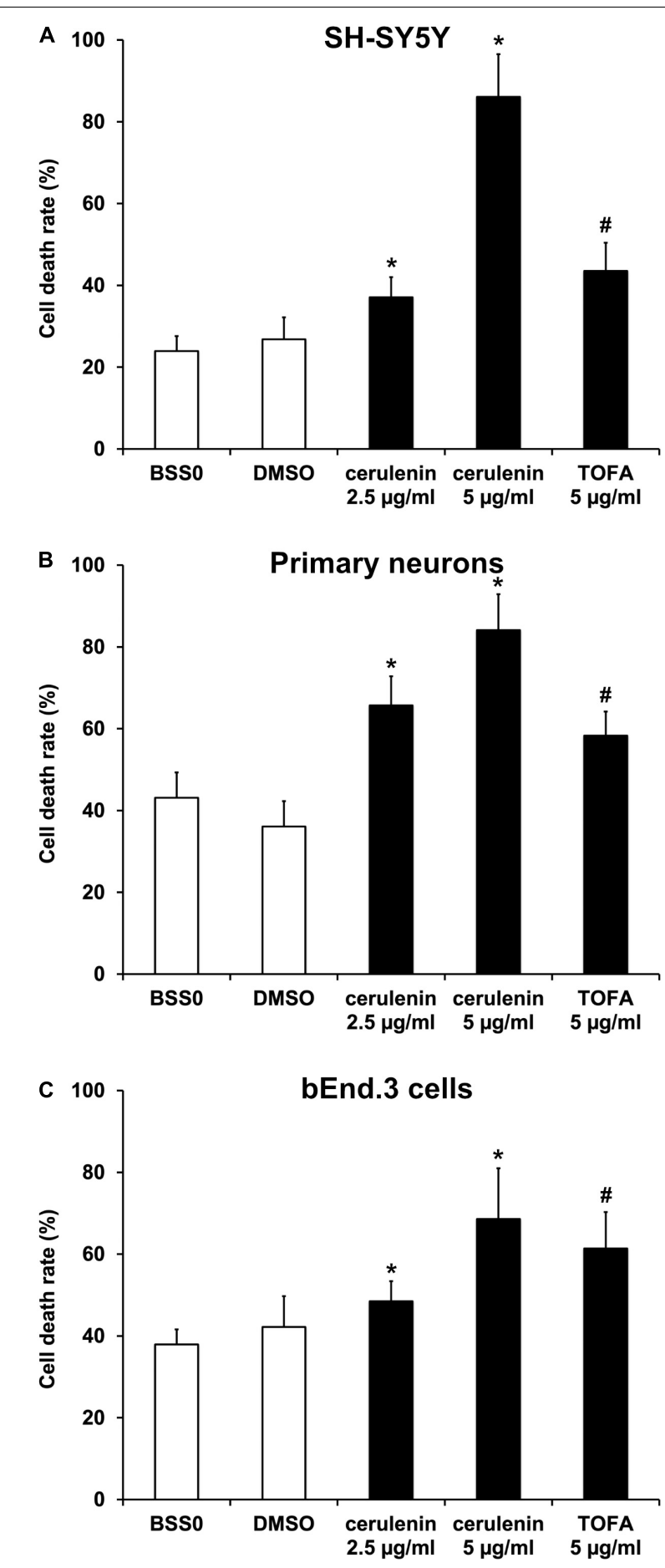

FIGURE 1 | Inhibition of FAS using cerulenin or TOFA aggravates cell death upon induction of oxygen-glucose-deprivation (OGD) in vitro. (A) Cultivated SH-SY5Y cells, (B) primary cortex cells, and (C) bEnd.3 cells were exposed to OGD and FAS inhibition by either cerulenin or TOFA ( $n=4$ per condition). The cells were exposed to OGD in BSSO solution for $10 \mathrm{~h} \mathbf{( A , B )}$ or $16 \mathrm{~h}$ (C) followed by reoxygenation for $24 \mathrm{~h}$ under standard cell culture conditions. BSSO served as control for TOFA, whereas cerulenin was dissolved in DMSO for which the latter served as control. The cell viability was analyzed using the MTT assay. \#Significantly different from BSSO control, $p<0.05$. *Significantly different from DMSO control, $p<0.05$. previously suggested (Paumen et al., 1997). As a matter of fact, ectopic delivery or overexpression of bcl-2 induces neuroprotection against cerebral ischemia (Kilic et al., 2002; Zhao et al., 2003; Doeppner et al., 2010; Zhang et al., 2015). Inhibition of FAS, on the contrary, leads to reduced endogenous bcl-2 levels, as demonstrated in bladder cancer cells (Jiang et al., 2012). However, the present study did not observe any regulation of bcl-2 in SH-SY5Y or primary cells exposed to OGD treated with either cerulenin or TOFA (data not shown), suggesting that increased cell death rates observed therein has to be mediated by other mechanisms.

Such other mechanisms involve the disruption of the BBB, which allows intravascular molecules and immune cells to penetrate into the extracellular compartment and into the brain parenchyma, reflecting a hallmark in cerebral ischemia (Dirnagl et al., 1999). In this context, various compounds are extruded through the barrier via ATP-binding cassette (ABC) transporters such as $\mathrm{ABCB} 1$. The latter is also highly regulated under stroke conditions, contributing to secondary cell injury as shown in preclinical stroke models (Spudich et al., 2006; Zhang et al., 2021). To analyze the impact of inhibition of FAS on the BBB, an in vitro co-culture model using endothelial cells and astrocytes was established.

When primary endothelial cells were seeded into 24-wells and kept under standard cell culture conditions, the transcellular electrical resistance (TER) significantly increased over time until it reached a plateau phase, indicating stable formation of the barrier (Figure 2A). Exposure to OGD, however, diminished TER values significantly in these endothelial cells as indicated by the cellZscopeE apparatus (Figure 2B). Administration of cerulenin (5 $\mu \mathrm{g} / \mathrm{ml}$ ) decreased TER levels upon OGD induction even further (Figure 2C). Mimicking BBB-like features, permeability coefficients were measured in the co-culture system consisting of primary astrocytes and primary endothelial cells. As a matter of fact, both EBA (large molecule) and LY (small molecule) permeability coefficients were significantly increased when cells were treated with cerulenin under hypoxic conditions, indicating enhanced leakage of the "BBB" (Figures 2D,E). Likewise, protein abundance of ABCB1 was significantly increased in the cerulenin group (Figure 2F). This data together with increased cell death rates of endothelial cells exposed to OGD (Figure 1C) is in favor of inhibition of FAS further enhancing leakage of the BBB under in vitro conditions.

\section{Inhibition of FAS Aggravates Brain Injury After Cerebral Ischemia in vivo}

Following the aforementioned in vitro results, the role of FAS was further analyzed in a rodent stroke model. When male C57BL6 mice were exposed to MCAO for $1 \mathrm{~h}$ followed by treatment with daily intraperitoneal cerulenin injections (50 $\mathrm{mg} / \mathrm{kg}$ body weight), mice displayed increased infarct volumes on day 4 poststroke (Figure 3A). The latter was confirmed using TUNEL staining analysis 7 days poststroke (Figure 3B). Long-term analysis revealed that treatment with cerulenin yielded significantly worsened behavioral outcome during the observation period of 4 weeks (Figures 3C-F). 

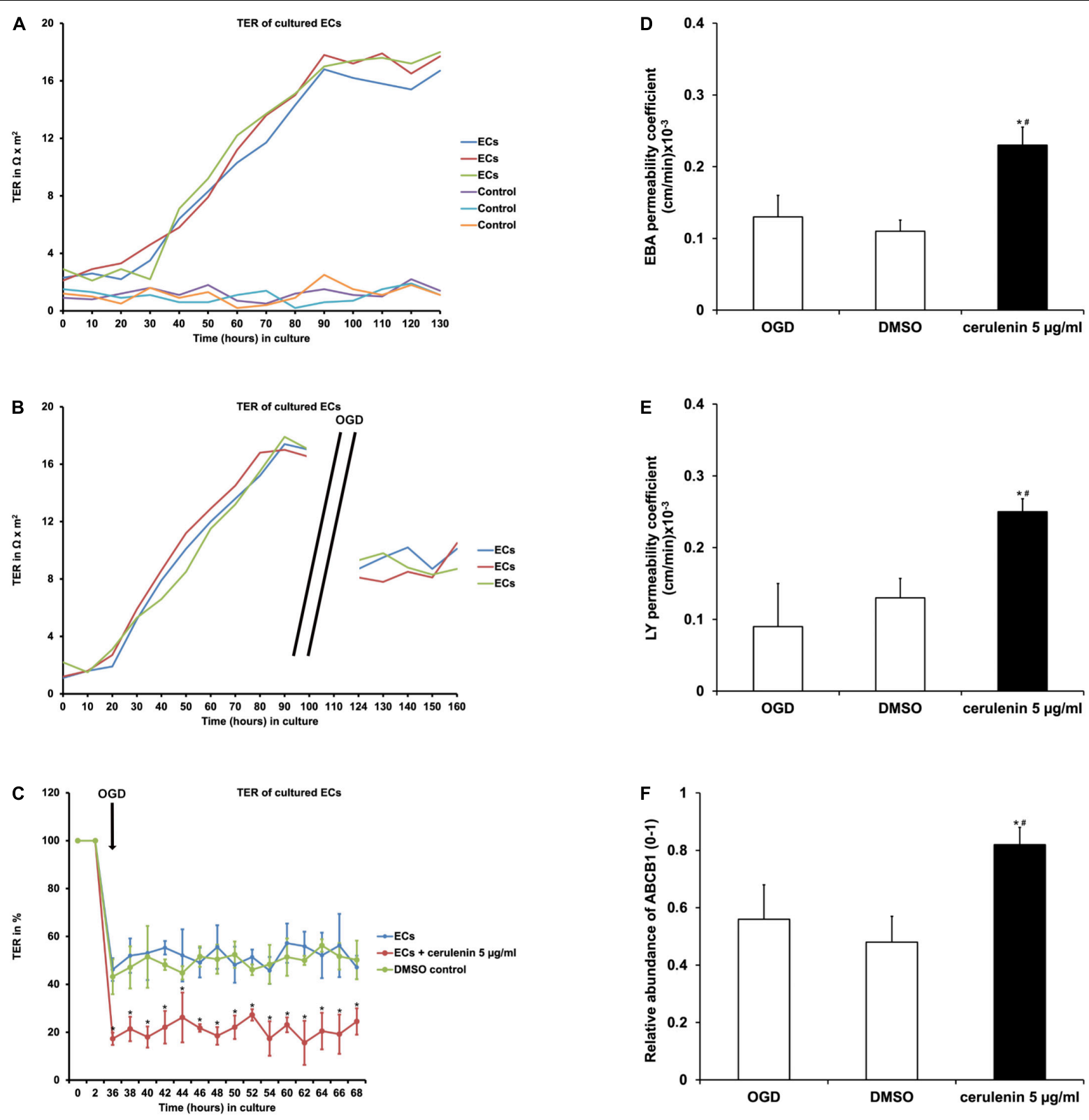

FIGURE 2 | Inhibition of FAS diminishes blood-brain barrier (BBB) integrity and increases the abundance of the ABCB1 transporter in primary endothelial cells. (A) Representative graphs depicting the extent of transcellular electrical resistance (TER) in primary endothelial cells (ECs) under standard cell culture conditions. Empty wells, i.e., wells containing no cells at all are referred to as "control," indicating background noise of the measurement. (B) Representative graphs for TER measurement in ECs exposed to oxygen-glucose-deprivation (OGD) injury followed by reoxygenation at standard cell culture conditions. Note that TER measurement was not possible during the OGD period itself due to technical limitations. (C) Measurement of TER in primary ECs exposed to OGD ( $n=4)$. Some cells were treated with cerulenin, whereas DMSO served as control. Pre-OGD values were set as 100\%. (D,E) Using a BBB co-culture model existing of both astrocytes and primary endothelial cells ( $n=4$ per condition), permeability coefficients for both Evans blue albumin (EBA; large molecule) and luciferase yellow (LY; small molecule) after OGD exposure were performed ( $n=4$ per condition). Administration of cerulenin significantly increases permeability coefficients in endothelial cells under hypoxic conditions when compared to DMSO controls. In line with this, protein abundance of ABCB1 is significantly increased when fatty acid synthase is blocked by cerulenin in endothelial cells $\mathbf{( F )}$. *Significantly different from DMSO control, $p<0.05$. "Significantly different from OGD samples, $p<0.05$.

The results obtained in the behavioral tests were backed up by an assessment of neuronal densities 4 weeks poststroke (Supplementary Figure 2). Inhibition of FAS significantly reduced neuronal densities in these stroke mice when compared to DMSO controls or sham animals.

\section{Reduction Potential Is Reduced by Inhibition of FAS}

Further analyses aimed to answer the question whether or not fatty acid inhibition affects the reduction potential upon induction of $\mathrm{OGD}$ in vitro or after $\mathrm{MCAO}$ in vivo. Previous 

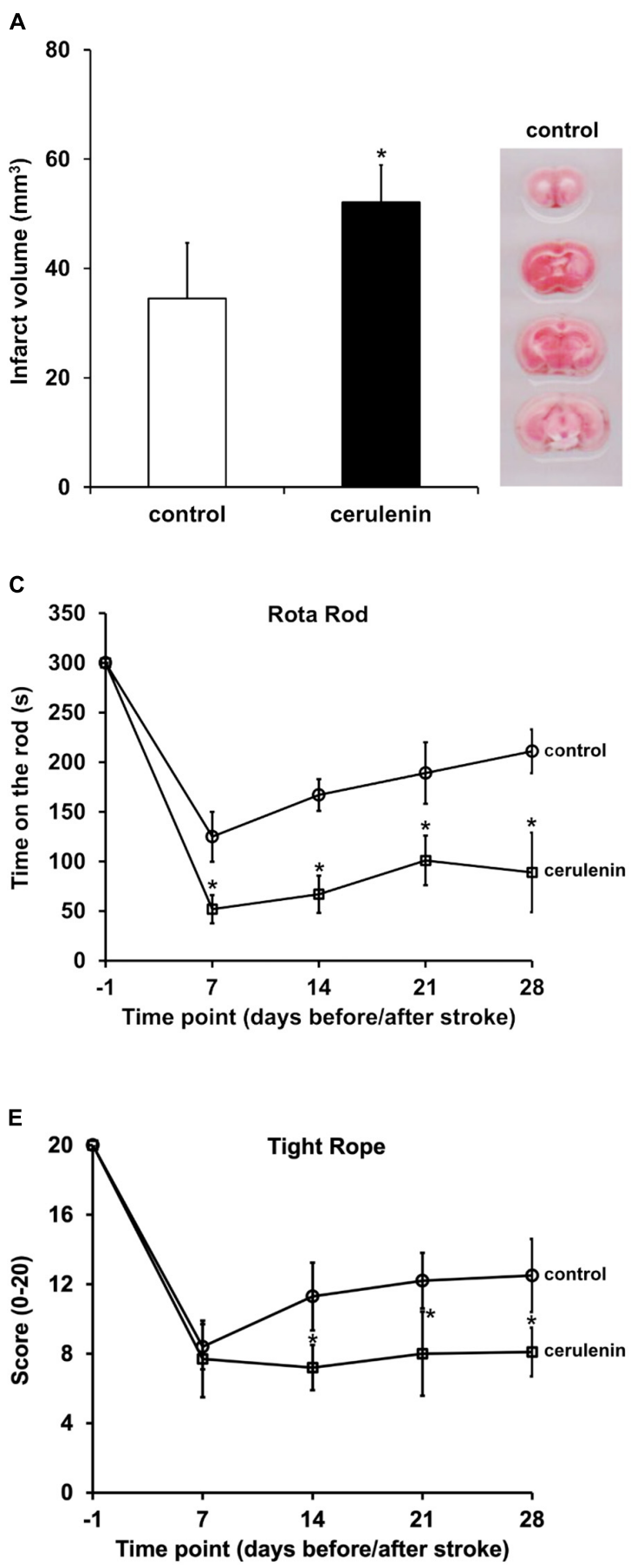

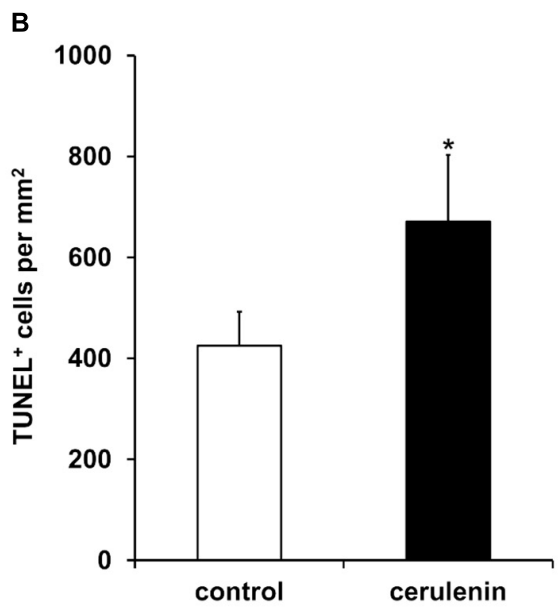

D
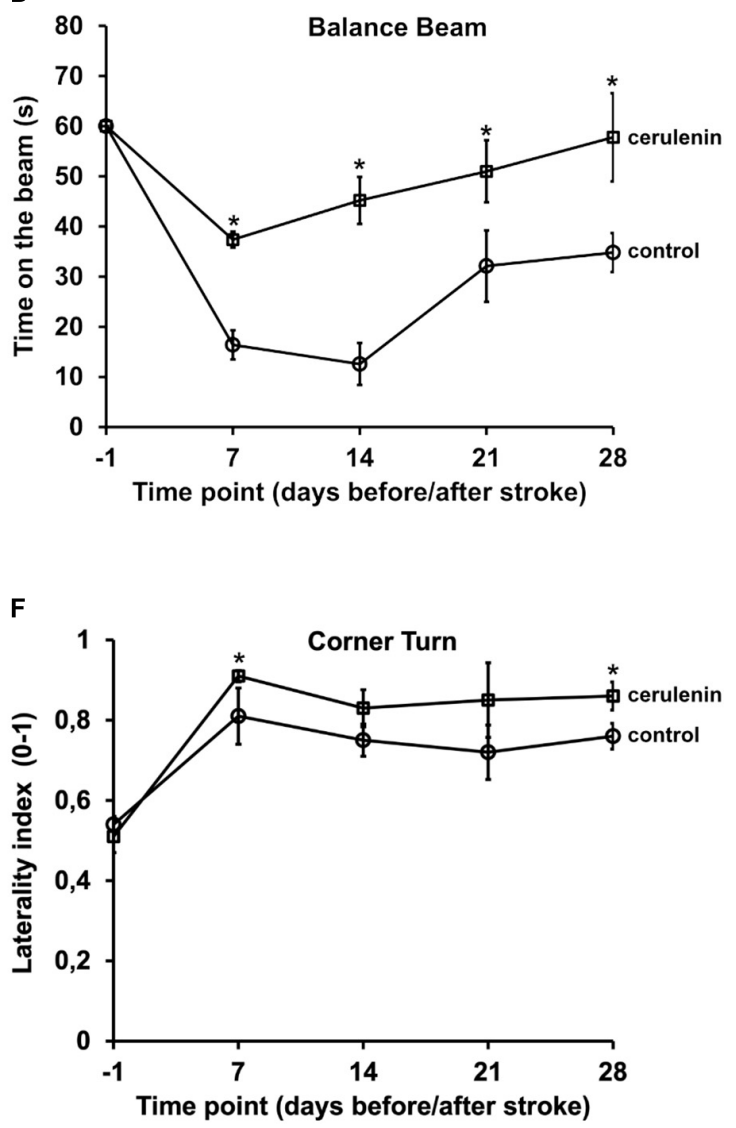

FIGURE 3 | Inhibition of FAS aggravates poststroke brain injury and motor coordination impairment. Mice were either treated with DMSO (control) or with cerulenin (50 mg/kg body weight). Brain injury was assessed using TTC staining ( $n=6$ per condition) on day 4 ( $\mathbf{A}$ ) or TUNEL staining ( $n=8$ per condition) on day 7 (B). Behavioral tests ( $n=21$ per condition) were performed during an observation period of 4 weeks at the time points given (circles: controls, squares: cerulenin). The tests included the rota rod $(\mathbf{C})$, balance beam $(\mathbf{D})$, tight rope $\mathbf{( E )}$, and corner turn test $\mathbf{( F )}$. All animals were trained before induction of stroke in order to ensure proper test performance. *Significantly different from controls, $p<0.05$.

work from Brose and colleagues (Brose et al., 2016) have already shown reduced reduction potentials in neuronal cells under hypoxic conditions. The latter, however, excluded a reoxygenation phase. Herein, exposure of neurons (SH-SY5Y cells and primary neurons) to OGD followed by $24 \mathrm{~h}$ of reoxygenation under standard cell culture conditions yielded an increased ratio of $\mathrm{NADH}_{2}{ }^{+} / \mathrm{NAD}^{+}$(Figures 4A,B), confirming the results obtained by Brose et al. $(2014,2016)$ under these 

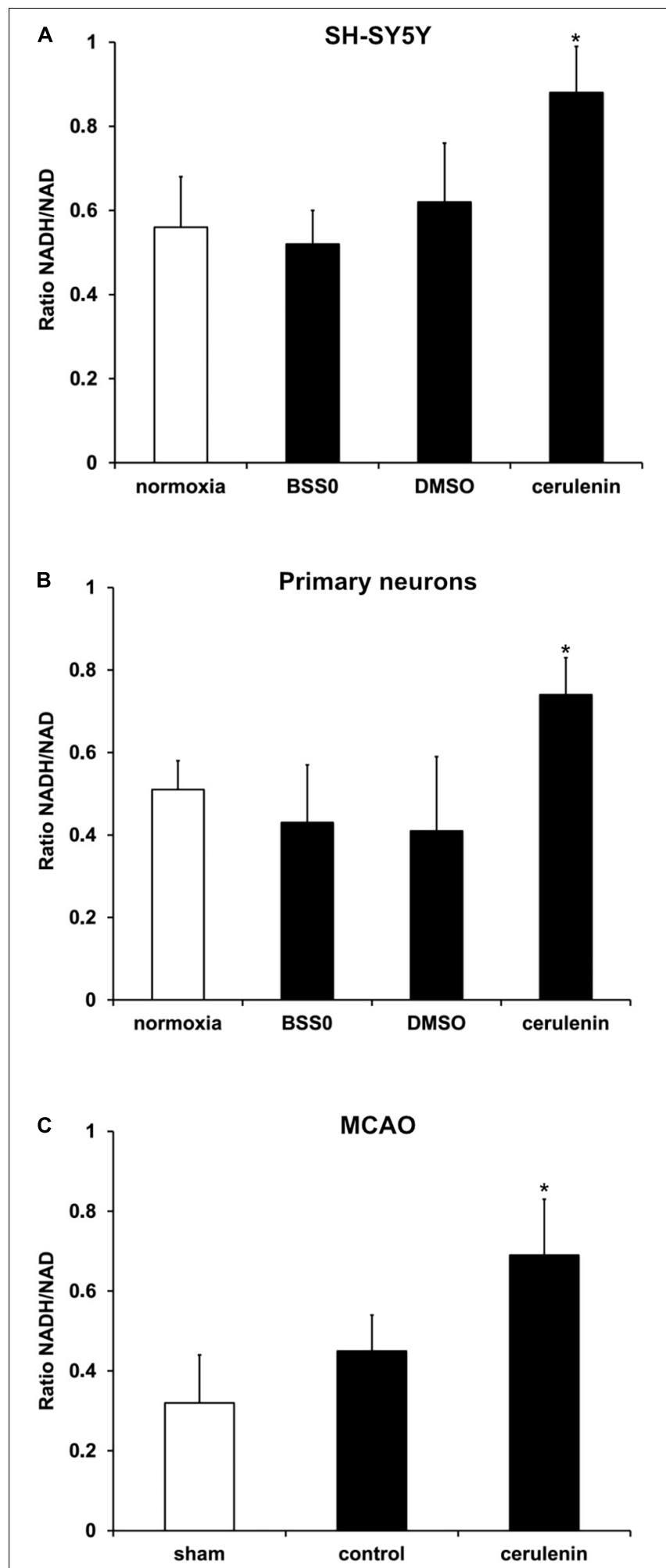

FIGURE 4 | Reduction potential is reduced by inhibition of FAS in SH-SY5Y cells, primary neurons and stroke mice. (A) Cultivated SH-SY5Y cells and (B) primary cortex cells were exposed to oxygen-glucose-deprivation (OGD) in BSSO solution for $10 \mathrm{~h}$ followed by reoxygenation for $24 \mathrm{~h}$ under standard cell culture conditions ( $n=4$ per condition). The cells were either treated with

(Continued)
FIGURE 4 | cerulenin or DMSO as control. Some cells were continuously kept under standard cell culture conditions ("normoxia") as a reference. The $\mathrm{NADH} / \mathrm{NAD}$ ratio was measured for each condition as given in "Materials and Method" section. (C) Measurement of the $\mathrm{NADH}_{2}{ }^{+} / \mathrm{NAD}^{+}$ratio on day 7 after induction of middle cerebral artery occlusion (MCAO) and daily injection of cerulenin ( $50 \mathrm{mg} / \mathrm{kg}$ body weight) in mice $(n=6)$. The control group received injections of DMSO only, whereas sham animals were not exposed to MCAO and did not receive any kind of treatment paradigm. *Significantly different from controls, $p<0.05$.

special conditions. Since the reduction potential has not been analyzed under in vivo stroke conditions by Brose and colleagues, $\mathrm{NADH}_{2}{ }^{+} / \mathrm{NAD}^{+}$ratios were also studied in stroke animals 7 days after induction of MCAO. Indeed, application of cerulenin also reduced the reduction potential in these animals when compared to DMSO controls (Figure 4C).

\section{Inhibition of FAS Enhances Poststroke BBB Leakage and Stimulates the NF- $\kappa$ B/Proteasome Pathway in vivo}

Application of cerulenin enhances BBB leakage and increases the abundance of the ABCB1 transporter under in vitro OGD conditions (Figure 2). Interestingly, exposure of mice to MCAO followed by treatment with cerulenin also yielded increased extravasation of Evans blue and enhanced the abundance of $\mathrm{ABCB} 1$ in these mice on day 1 poststroke (Figures $\mathbf{5 A}, \mathbf{B}$ and Supplementary Figure 3 ). The degradation of the BBB upon stroke induction is, however, not only a consequence of the $\mathrm{ABCB} 1$ transporter but is also critically mediated by the activity of matrix metalloproteases (MMP) that play in concert with a plethora of other signaling cascades (Lakhan et al., 2013). Indeed, stroke enhanced both protein abundance and activity of MMP9 at $24 \mathrm{~h}$ poststroke when compared to sham mice, which was even further enhanced when mice were treated with cerulenin (Figures 5C,D and Supplementary Figure 3).

Accumulating evidence suggests that ABCB1 transporters as well as MMP-9 activity are regulated by the nuclear factorkappa B (NF-кB) signaling pathway under non-stroke conditions (Nakanishi and Toi, 2005; Katayama et al., 2014; Chiu et al., 2015; Andersson et al., 2018). Whereas the role of NF- $\kappa$ B and the proteasome under stroke conditions has already been shown (Ridder and Schwaninger, 2009; Harari and Liao, 2010; Doeppner et al., 2013; Lv et al., 2019), the mutual interaction between MMP9 and $\mathrm{ABCB} 1$ on the one hand and NF- $\mathrm{B}$ on the other hand has just recently been described by us in a murine stroke model (Zhang et al., 2021). Whether or not the inhibition of the fatty acid synthase by means of cerulenin under such conditions also interferes with the aforementioned signaling pathways is not yet known. As a matter of fact, stroke itself increased both NF$\kappa \mathrm{B}$ p65 abundance and proteasome activity $24 \mathrm{~h}$ after stroke induction (Figures 5E,F and Supplementary Figure 3), as was expected. Treatment of stroke mice with cerulenin, however, further increased NF- $\mathrm{B}$ p 65 abundance and proteasome activity when compared to control mice. 

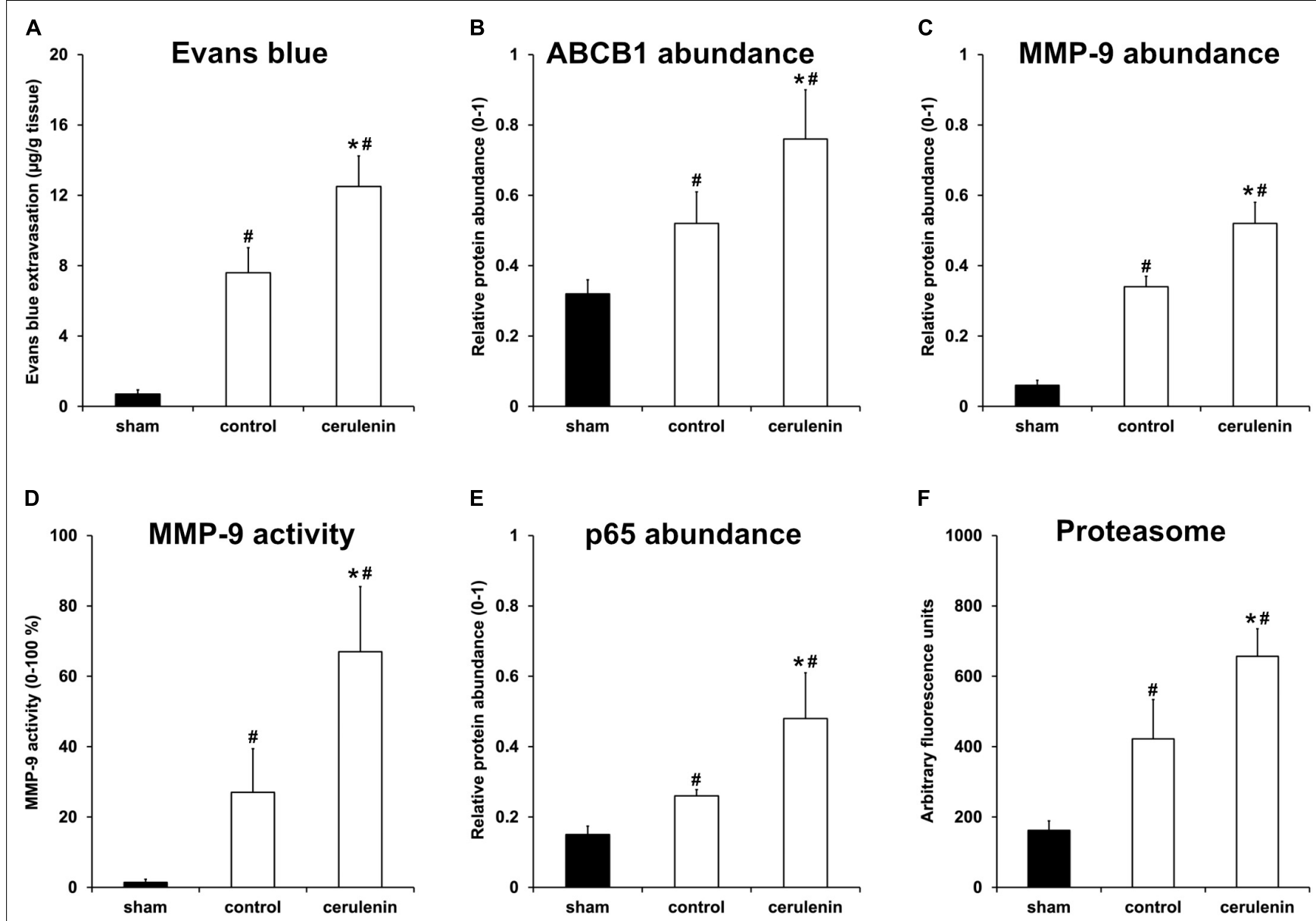

FIGURE 5 | Inhibition of FAS enhances poststroke BBB leakage and stimulates the NF-kB/proteasome pathway in vivo. All mice ( $n=9$ per condition) were exposed to middle cerebral artery occlusion (MCAO) followed by cerulenin treatment or DMSO application (controls). Sham mice underwent the same surgical procedure but without MCAO. End of the experiments was $24 \mathrm{~h}$ after induction of MCAO. Blood-brain barrier (BBB) leakage was measured via Evans blue extravasation (A), whereas ABCB1 (B) and MMP-9 (C) abundance was analyzed by means of Western blotting. MMP-9 activity itself was studied using a gelatin zymography assay (D). The NF-кB protein abundance was measured using a Western blot against p65 within the ischemic hemispheres (E). Proteasomal activity was measured using a fluorimetric assay, as described in section "Materials and Methods" (F). *Significantly different from controls, $p<0.05$. \# Significantly different from sham mice, $p<0.05$.

\section{FAS Inhibition Stimulates Poststroke Inflammatory Responses in vivo}

Inflammation critically contributes to secondary stroke injury during the subacute phase of the disease as mentioned before. Besides, the NF- $\mathrm{BB} /$ proteasome signaling pathway, which is significantly stimulated upon treatment with cerulenin (Figure 5), regulates proinflammatory cell cascades on its own (Phillips et al., 2000; Zhang et al., 2010, 2016; Doeppner et al., 2015). Indeed, inhibition of FAS not only resulted in increased glial scar formation (Figure 6A) and microglial response (Figure 6B), but also in a significantly enhanced inflammatory reaction within the ischemic hemisphere 7 days after stroke induction. Flow cytometry analyses on that day revealed increased stroke-induced numbers of total leukocytes, neutrophils as well as of B and T lymphocytes (Figures 6C-F). Of note, cerulenin treatment further increased cell numbers of all of these cell populations.

\section{DISCUSSION}

The present work aimed to illuminate whether or not the inhibition of FAS represents a biologically relevant pathway under preclinical in vitro and in vivo stroke conditions. Although recent findings demonstrated that the inhibition of FAS yields an increased cell death rate and a decreased reduction potential, the work published by Brose et al. (2016) used an in vitro model of hypoxia only. Herein, the role of FAS was therefore studied in a hypoxia/reoxygenation model in vitro as well as under in vivo stroke conditions, emphasizing the role of the $\mathrm{BBB}$ and poststroke inflammatory tissue response.

Exposure of SH-SY5Y neuroblastoma cells and primary neurons to in vitro hypoxia results in a prominent cell death rate. Irreversible inhibition of fatty acid synthase by covalent binding to the $\beta$-ketoacyl synthase domain (Zhao et al., 2006; Furuta et al., 2008; Murata et al., 2010) using cerulenin or inhibition 

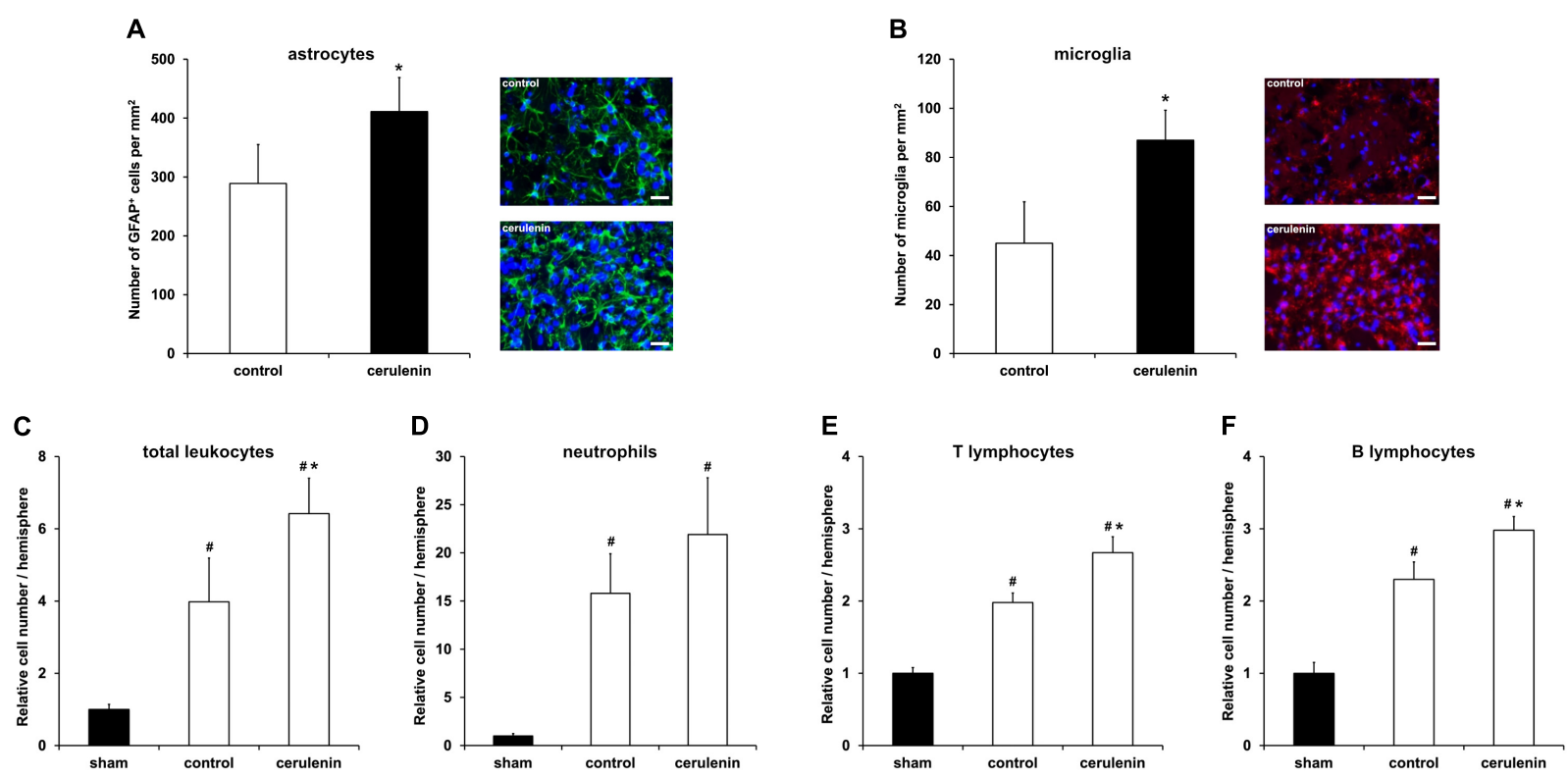

FIGURE 6 | FAS inhibition stimulates poststroke inflammatory responses in vivo. Mice were exposed to middle cerebral artery occlusion (MCAO) and allowed to survive for 7 days after induction of MCAO ( $n=11$ per condition). The animals received either cerulenin or DMSO as control, as explained in detail in "Materials and Methods" section. Immunohistochemical analyses for astroglia and microglia was performed using either GFAP (A, green) or Iba1 staining (B, red). DAPI counterstaining (blue) was performed in parallel. Scale bars are $50 \mu \mathrm{m}$. Using flow cytometry, the numbers of total leukocytes (C), neutrophils (D), T lymphocytes (E) and B lymphocytes (F) were measured on day 7 in ischemic hemispheres. ${ }^{\star}$ Significantly different from controls, $p<0.05 .{ }^{\#}$ Significantly different from sham mice, $p<0.05$.

of Acetyl-CoA carboxylase by means of TOFA increases cell death even further. Hence, inhibition of FAS confirms previously published data by Brose et al. $(2014,2016)$ in our in vitro stroke model. The present work, for the first time, demonstrates a biologically relevant role of FAS under in vivo stroke conditions. Cerulenin treatment not only resulted in increased histological brain injury upon induction of stroke, but also yielded decreased neurological recovery in these animals during the observation period of 4 weeks.

Nicotinamide adenine dinucleotide (NAD) serves as a cofactor in more than 250 redox reactions, among which are reaction pathways of the glycolysis and the citrate cycle (Heinrich et al., 2014). Under physiological conditions, $\mathrm{NAD}^{+}$ is reduced to $\mathrm{NADH}_{2}{ }^{+}$followed by its reoxidation while passing the respiratory chain to build up a proton gradient. During oxidative phosphorylation, oxygen is transferred to two protons and as such, one water molecule is generated as a side product. Accordingly, this mechanism and thus the ATP synthesis by oxidative phosphorylation come to a halt under hypoxia. Consequently, $\mathrm{NADH}_{2}{ }^{+}$cannot be reoxidated via this pathway. This condition is reflected by the increased ratio of $\mathrm{NADH}_{2}{ }^{+} / \mathrm{NAD}^{+}$under both in vitro and in vivo stroke conditions as observed in the present work, emphasizing that hypoxia and simultaneous inhibition of FAS negatively affect the cell redox potential. Indeed, application of NAD in a model of transient focal cerebral ischemia has been found to improve neurological outcome (Ying et al., 2007), leading to the assumption that preservation of the redox potential represents a valid goal. These findings are in line with the results by
Brose et al. (2016), emphasizing that the inhibition of FAS further limits the potential to reoxidize $\mathrm{NADH}_{2}{ }^{+}$.

Inhibition of FAS is not only limited to regulating $\mathrm{NADH}_{2}{ }^{+} / \mathrm{NAD}^{+}$ratios but also affects other signaling pathways as well. Fatty acids derive from malonyl-CoA, an inhibitor of carnitine palmityl transferase 1 , which itself represents the rate-limiting enzyme of beta oxidation. The close proximity of carnitine palmityl transferase 1 at the outer mitochondrial membrane with the antiapoptotic protein bcl-2 suggest a mutual interaction between the two proteins (Paumen et al., 1997). Bcl-2 has been widely studied in various models of cerebral ischemia where it exerts neuroprotection (Kilic et al., 2002; Zhao et al., 2003; Doeppner et al., 2010; Zhang et al., 2015), and bcl-2 deficient mice display prominent infarct volumes and an aggravated neurological deficit compared to wild type mice (Akhtar et al., 2004). Interestingly, the overexpression of antiapoptotic bcl-2 in glioblastoma cells partly compensates the proapoptotic effect of cerulenin (Zhao et al., 2006). At the same time, data suggests that hypoxia is associated with an increased expression of bcl-2. Inhibition of FAS leads, however, to reduced endogenous bcl-2 levels, as demonstrated in bladder cancer cells (Jiang et al., 2012). Herein, bcl-2 levels were not affected by FAS inhibition, neither in SH-SY5Y cells nor in primary neurons exposed to OGD (own unpublished observation).

Inhibition of FAS is unlikely to affect a single pathway only, if at all, as is the case for bcl-2. Since stroke-induced loss of $\mathrm{BBB}$ integrity during the acute phase is of uttermost importance for the course of the disease, studying BBB leakage under both in vitro and in vivo stroke conditions was analyzed in the presence 
of FAS inhibition. Whereas some data suggests a role of FAS in the context of endothelial cell proliferation and angiogenesis specifically under neoplastic conditions (Browne et al., 2006; Zaytseva et al., 2014; Bastos et al., 2017; Singh et al., 2017; Bruning et al., 2018), such aspects have not been addressed in endothelial cells exposed to an in vitro or in vivo stroke model. Not only does inhibition of FAS result in increased cell death rates of endothelial cells under hypoxic but not so under normoxic conditions, which is in line with cytotoxicity studies in tumors, but also result in increased interendothelial cell leakage. The latter is associated with decreased levels of TER in cultured endothelial cells treated with cerulenin under hypoxic conditions, underlining the aggravation of hypoxia-induced BBB breakdown upon inhibition of FAS. On the molecular level, posthypoxic/postischemic BBB breakdown is linked with an upregulation of ABCB1 transporters and MMP-9 activity (Fujimura et al., 1999; Spudich et al., 2006; Park et al., 2009; ElAli and Hermann, 2012; Suofu et al., 2012; Cen et al., 2013; Ji et al., 2013; Qosa et al., 2015; Song et al., 2015; Rempe et al., 2016; Turner and Sharp, 2016; Yang and CandelarioJalil, 2017; Zhang et al., 2021), and knockdown of ABCB1 or pharmacological inhibition of the transporter reduces poststroke brain injury and ameliorates functional outcome (Spudich et al., 2006; Murozono et al., 2009).

Recent work from our group has established a causal link between increased activity of both ABCB1 and MMP-9 on the one hand and the NF- $\kappa$ B pathway on the other hand under stroke conditions (Zhang et al., 2021). Using a murine stroke model, our group was able to show that stimulation of the proinflammatory NF- $\kappa$ B pathway results in both enhanced MMP-9 activity and increased $\mathrm{ABCB} 1$ transporter activity, all of which leading to $\mathrm{BBB}$ breakdown, cell death and impaired neurological recovery. The present work was able to show that inhibition of FAS also affects the NF- $\mathrm{B}$ pathway where p65 protein abundance as well as proteasomal activity are significantly increased due to cerulenin treatment. Increased levels of NF- $\mathrm{B}-\mathrm{p} 65$ together with enhanced activity of the proteasome, in turn, not only mediate the aforementioned loss of BBB integrity but also activate a plethora of proinflammatory signaling cascades (Phillips et al., 2000; Zhang et al., 2006, 2010; Doeppner et al., 2015). Hence, cerulenin treatment significantly increases microglial activity and enhances overall leukocyte numbers as well as defined subpopulations of leukocytes within the ischemic hemisphere. Such an increased proinflammatory status within the brain due to FAS inhibition further supports secondary brain injury upon stroke induction, culminating in reduced neurological recovery of stroke animals.

The present data for the first time demonstrates the important role of FAS under both in vitro and in vivo stroke conditions, depicting the fatal consequences of inhibition of FAS with regard to BBB integrity, brain injury, and neurological recovery. Nevertheless, cerulenin application and

\section{REFERENCES}

Akhtar, R. S., Ness, J. M., and Roth, K. A. (2004). Bcl-2 family regulation of neuronal development and neurodegeneration. Biochim. Biophys. Acta BBA Mol. Cell Res. 1644, 189-203. doi: 10.1016/j.bbamcr.2003. 10.013 subsequent FAS inhibition will not only affect the aforementioned signaling cascades but also downstream signaling such as lipid peroxidation. Inhibition of the latter is known to be neuroprotective against stroke, decreasing oxidative stress and further reducing BBB leakage (Yigitkanli et al., 2013; Karatas et al., 2018). In this context, cerulenin does not only irreversibly inhibit fatty acid synthase but also inhibits HMG-CoA synthetase and thus steroid biosynthesis (Nomura et al., 1972), albeit some data indicates that this effect might depend on the species studied (Greenspan and Mackow, 1977). Since both FAS inhibitors used in the present study, i.e., TOFA and cerulenin, pronounced cell injury, it stands to reason that the effects observed herein are attributed to FAS inhibition itself, rather than to side effects of either inhibitor. Yet, additional studies are in order, analyzing the dynamic flux of FAS and bioavailability of fatty acids, both in the central nervous system but also in peripheral organs. Such studies were, however, beyond the scope of the present work.

\section{DATA AVAILABILITY STATEMENT}

The raw data supporting the conclusions of this article will be made available by the authors, without undue reservation.

\section{ETHICS STATEMENT}

The animal study was reviewed and approved by the Medipol University Istanbul LAVES.

\section{AUTHOR CONTRIBUTIONS}

LJ and TD designed and conceptualized the study. XA, XZ, WW, AC, Y-cW, and VV performed experiments, data analysis, and interpretation. $\mathrm{EK}, \mathrm{TD}$, and $\mathrm{MB}$ provided financial support and infrastructure. $\mathrm{LJ}, \mathrm{TD}, \mathrm{DH}, \mathrm{MB}$, and $\mathrm{EK}$ wrote the manuscript. All authors contributed to the article and approved the submitted version.

\section{ACKNOWLEDGMENTS}

We thank Irina Graf for excellent technical assistance.

\section{SUPPLEMENTARY MATERIAL}

The Supplementary Material for this article can be found online at: https://www.frontiersin.org/articles/10.3389/fncel. 2021.733973/full\#supplementary-material

Andersson, P., Yang, Y., Hosaka, K., Zhang, Y., Fischer, C., Braun, H., et al. (2018). Molecular mechanisms of IL-33-mediated stromal interactions in cancer metastasis. JCI Insight 3:122375. doi: 10.1172/jci.insight.122375

Assmann, J. C., Müller, K., Wenzel, J., Walther, T., Brands, J., Thornton, P., et al. (2017). Isolation and Cultivation of Primary Brain Endothelial Cells from Adult Mice. Bio Protoc. 7:e2294. doi: 10.21769/BioProtoc.2294 
Bastos, D. C., Paupert, J., Maillard, C., Seguin, F., Carvalho, M. A., Agostini, M., et al. (2017). Effects of fatty acid synthase inhibitors on lymphatic vessels: an in vitro and in vivo study in a melanoma model. Lab. Investig. J. Tech. Methods Pathol. 97, 194-206. doi: 10.1038/labinvest.2016.125

Brose, S. A., Golovko, S. A., and Golovko, M. Y. (2016). Fatty Acid Biosynthesis Inhibition Increases Reduction Potential in Neuronal Cells under Hypoxia. Front. Neurosci. 10:546. doi: 10.3389/fnins.2016.00546

Brose, S. A., Marquardt, A. L., and Golovko, M. Y. (2014). Fatty acid biosynthesis from glutamate and glutamine is specifically induced in neuronal cells under hypoxia. J. Neurochem. 129, 400-412. doi: 10.1111/jnc.12617

Browne, C. D., Hindmarsh, E. J., and Smith, J. W. (2006). Inhibition of endothelial cell proliferation and angiogenesis by orlistat, a fatty acid synthase inhibitor. FASEB J. Off. Publ. Fed. Am. Soc. Exp. Biol. 20, 2027-2035. doi: 10.1096/fj.05$5404 \mathrm{com}$

Bruning, U., Morales-Rodriguez, F., Kalucka, J., Goveia, J., Taverna, F., Queiroz, K. C. S., et al. (2018). Impairment of Angiogenesis by Fatty Acid Synthase Inhibition Involves mTOR Malonylation. Cell Metab. 28, 866.e-880.e. doi: 10. 1016/j.cmet.2018.07.019

Cen, J., Liu, L., Li, M.-S., He, L., Wang, L.-J., Liu, Y.-Q., et al. (2013). Alteration in P-glycoprotein at the blood-brain barrier in the early period of MCAO in rats. J. Pharm. Pharmacol. 65, 665-672. doi: 10.1111/jphp.12033

Chiu, C.-T., Chen, J.-H., Chou, F.-P., and Lin, H.-H. (2015). Hibiscus sabdariffa Leaf Extract Inhibits Human Prostate Cancer Cell Invasion via DownRegulation of Akt/NF-kB/MMP-9 Pathway. Nutrients 7, 5065-5087. doi: 10. 3390/nu7075065

Chu, H. X., Kim, H. A., Lee, S., Moore, J. P., Chan, C. T., Vinh, A., et al. (2014). Immune cell infiltration in malignant middle cerebral artery infarction: comparison with transient cerebral ischemia. J. Cereb. Blood Flow Metab. Off. J. Int. Soc. Cereb. Blood Flow Metab. 34, 450-459. doi: 10.1038/jcbfm.2013.217

Czupalla, C. J., Liebner, S., and Devraj, K. (2014). In vitro models of the blood-brain barrier. Methods Mol. Biol. 1135, 415-437. doi: 10.1007/978-1-4939-0320-7_34

Dehouck, M. P., Jolliet-Riant, P., Brée, F., Fruchart, J. C., Cecchelli, R., and Tillement, J. P. (1992). Drug transfer across the blood-brain barrier: correlation between in vitro and in vivo models. J. Neurochem. 58, 1790-1797. doi: 10.1111/ j.1471-4159.1992.tb10055.x

Dirnagl, U., Iadecola, C., and Moskowitz, M. A. (1999). Pathobiology of ischaemic stroke: an integrated view. Trends Neurosci. 22, 391-397. doi: 10.1016/S01662236(99)01401-0

Doeppner, T. R., El Aanbouri, M., Dietz, G. P. H., Weise, J., Schwarting, S., and Bähr, M. (2010). Transplantation of TAT-Bcl-xL-transduced neural precursor cells: Long-term neuroprotection after stroke. Neurobiol. Dis. 40, 265-276. doi: 10.1016/j.nbd.2010.05.033

Doeppner, T. R., Herz, J., Gorgens, A., Schlechter, J., Ludwig, A.-K., Radtke, S., et al. (2015). Extracellular Vesicles Improve Post-Stroke Neuroregeneration and Prevent Postischemic Immunosuppression. Stem Cells Transl. Med. 4, 1131-1143. doi: 10.5966/sctm.2015-0078

Doeppner, T. R., Kaltwasser, B., Bähr, M., and Hermann, D. M. (2014a). Effects of neural progenitor cells on post-stroke neurological impairment - a detailed and comprehensive analysis of behavioral tests. Front. Cell. Neurosci. 8:00338. doi: $10.3389 /$ fncel.2014.00338

Doeppner, T. R., Kaltwasser, B., ElAli, A., Zechariah, A., Hermann, D. M., and Bähr, M. (2011). Acute hepatocyte growth factor treatment induces longterm neuroprotection and stroke recovery via mechanisms involving neural precursor cell proliferation and differentiation. J. Cereb. Blood Flow Metab. Off. J. Int. Soc. Cereb. Blood Flow Metab. 31, 1251-1262. doi: 10.1038/jcbfm.2010.211

Doeppner, T. R., Kaltwasser, B., Fengyan, J., Hermann, D. M., and Bähr, M. (2013). TAT-Hsp70 induces neuroprotection against stroke via anti-inflammatory actions providing appropriate cellular microenvironment for transplantation of neural precursor cells. J. Cereb. Blood Flow Metab. Off. J. Int. Soc. Cereb. Blood Flow Metab. 33, 1778-1788. doi: 10.1038/jcbfm.2013.126

Doeppner, T. R., Kaltwasser, B., Teli, M. K., Bretschneider, E., Bähr, M., and Hermann, D. M. (2014b). Effects of acute versus post-acute systemic delivery of neural progenitor cells on neurological recovery and brain remodeling after focal cerebral ischemia in mice. Cell Death Dis. 5, e1386-e1386. doi: 10.1038/ cddis. 2014.359

Doeppner, T. R., Mlynarczuk-Bialy, I., Kuckelkorn, U., Kaltwasser, B., Herz, J., Hasan, M. R., et al. (2012). The novel proteasome inhibitor BSc2118 protects against cerebral ischaemia through HIF1A accumulation and enhanced angioneurogenesis. Brain 135, 3282-3297. doi: 10.1093/brain/aws269

Eigenmann, D. E., Xue, G., Kim, K. S., Moses, A. V., Hamburger, M., and Oufir, M. (2013). Comparative study of four immortalized human brain capillary endothelial cell lines, hCMEC/D3, hBMEC, TY10, and BB19, and optimization of culture conditions, for an in vitro blood-brain barrier model for drug permeability studies. Fluids Barriers CNS 10:33. doi: 10.1186/2045-8118-10-33

ElAli, A., and Hermann, D. M. (2012). Liver X receptor activation enhances bloodbrain barrier integrity in the ischemic brain and increases the abundance of ATP-binding cassette transporters ABCB1 and ABCC1 on brain capillary cells. Brain Pathol. Zurich Switz. 22, 175-187. doi: 10.1111/j.1750-3639.2011.00517.x

Fujimura, M., Gasche, Y., Morita-Fujimura, Y., Massengale, J., Kawase, M., and Chan, P. H. (1999). Early appearance of activated matrix metalloproteinase-9 and blood-brain barrier disruption in mice after focal cerebral ischemia and reperfusion. Brain Res. 842, 92-100. doi: 10.1016/s0006-8993(99)01843-0

Furuta, E., Pai, S. K., Zhan, R., Bandyopadhyay, S., Watabe, M., Mo, Y.-Y., et al. (2008). Fatty Acid Synthase Gene Is Up-regulated by Hypoxia via Activation of Akt and Sterol Regulatory Element Binding Protein-1. Cancer Res. 68, 1003-1011. doi: 10.1158/0008-5472.CAN-07-2489

Greenspan, M. D., and Mackow, R. C. (1977). The effct of cerulenin on sterol biosynthesis in Saccharomyces cerevisiae. Lipids 12, 729-740. doi: 10.1007/ BF02570903

Harari, O. A., and Liao, J. K. (2010). NF-кB and innate immunity in ischemic stroke. Ann. N Y. Acad. Sci. 1207, 32-40. doi: 10.1111/j.1749-6632.2010.05735.x

Heinrich, P. C., Müller, M., Graeve, L., Löffler, G., and Petrides, P. E. (eds) (2014). Löffler/Petrides Biochemie und Pathobiochemie. Berlin: Springer.

$\mathrm{Hu}, \mathrm{X}$., and Beeton, C. (2010). Detection of functional matrix metalloproteinases by zymography. J. Vis. Exp. JoVE 2010:2445. doi: 10.3791/2445

Ji, B.-S., Cen, J., He, L., Liu, M., Liu, Y.-Q., and Liu, L. (2013). Modulation of P-glycoprotein in rat brain microvessel endothelial cells under oxygen glucose deprivation. J. Pharm. Pharmacol. 65, 1508-1517. doi: 10.1111/jphp.12122

Jiang, B., Li, E.-H., Lu, Y.-Y., Jiang, Q., Cui, D., Jing, Y.-F., et al. (2012). Inhibition of Fatty-acid Synthase Suppresses P-AKT and Induces Apoptosis in Bladder Cancer. Urology 80, .e9-.e484. doi: 10.1016/j.urology.2012.02.046

Karatas, H., Eun Jung, J., Lo, E. H., and van Leyen, K. (2018). Inhibiting 12/15lipoxygenase to treat acute stroke in permanent and tPA induced thrombolysis models. Brain Res. 1678, 123-128. doi: 10.1016/j.brainres.2017.10.024

Katayama, K., Noguchi, K., and Sugimoto, Y. (2014). Regulations of P-Glycoprotein/ABCB1/ MDR1 in Human Cancer Cells. New J. Sci. 2014, 1-10. doi: 10.1155/2014/476974

Kilic, E., Dietz, G. P. H., Hermann, D. M., and Bähr, M. (2002). Intravenous TAT$\mathrm{Bcl}-\mathrm{Xl}$ is protective after middle cerebral artery occlusion in mice. Ann. Neurol. 52, 617-622. doi: 10.1002/ana.10356

Kuzmanov, I., Herrmann, A. M., Galla, H.-J., Meuth, S. G., Wiendl, H., and Klotz, L. (2016). An In Vitro Model of the Blood-brain Barrier Using Impedance Spectroscopy: A Focus on T Cell-endothelial Cell Interaction. J. Vis. Exp. 2016:54592. doi: 10.3791/54592

Lakhan, S. E., Kirchgessner, A., Tepper, D., and Leonard, A. (2013). Matrix metalloproteinases and blood-brain barrier disruption in acute ischemic stroke. Front. Neurol. 4:32. doi: 10.3389/fneur.2013.00032

Levine, S. R. (2004). Pathophysiology and therapeutic targets for ischemic stroke. Clin. Cardiol. 27, 12-24. doi: 10.1002/clc.4960271404

Lv, Y., Liu, W., Ruan, Z., Xu, Z., and Fu, L. (2019). Myosin IIA Regulated Tight Junction in Oxygen Glucose-Deprived Brain Endothelial Cells Via Activation of

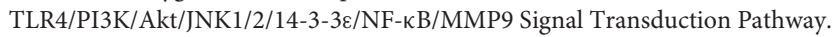
Cell. Mol. Neurobiol. 39, 301-319. doi: 10.1007/s10571-019-00654-y

Maherally, Z., Fillmore, H. L., Tan, S. L., Tan, S. F., Jassam, S. A., Quack, F. I., et al. (2018). Real-time acquisition of transendothelial electrical resistance in an all-human, in vitro, 3-dimensional, blood-brain barrier model exemplifies tight-junction integrity. FASEB J. Off. Publ. Fed. Am. Soc. Exp. Biol. 32, 168-182. doi: 10.1096/fj.201700162R

Matsumae, A., Kamio, Y., and Hata, T. (1963). Studies on cerulenin. I. Studies on cerulenin producing strain. J. Antibiot. 16, 236-238.

Murata, S., Yanagisawa, K., Fukunaga, K., Oda, T., Kobayashi, A., Sasaki, R., et al. (2010). Fatty acid synthase inhibitor cerulenin suppresses liver metastasis of colon cancer in mice. Cancer Sci. 101, 1861-1865. doi: 10.1111/j.1349-7006. 2010.01596.x 
Murozono, M., Matsumoto, S., Okada, S., Nagaoka, D., Isshiki, A., and Watanabe, Y. (2009). Reduction of brain infarction induced by a transient brain ischemia in mdrla knockout mice. Neurochem. Res. 34, 1555-1561. doi: 10.1007/s11064009-9943-6

Nakamura, K., and Shichita, T. (2019). Cellular and molecular mechanisms of sterile inflammation in ischaemic stroke. J. Biochem. 165, 459-464. doi: 10.1093/ $\mathrm{jb} / \mathrm{mvz} 017$

Nakanishi, C., and Toi, M. (2005). Nuclear factor-kappaB inhibitors as sensitizers to anticancer drugs. Nat. Rev. Cancer 5, 297-309. doi: 10.1038/nrc1588

Nomura, S., Horiuchi, T., Omura, S., and Hata, T. (1972). The action mechanism of cerulenin. I. Effect of cerulenin on sterol and fatty acid biosynthesis in yeast. J. Biochem. 71, 783-796. doi: 10.1093/oxfordjournals.jbchem.a129827

Omura, S. (1976). The antibiotic cerulenin, a novel tool for biochemistry as an inhibitor of fatty acid synthesis. Bacteriol. Rev. 40, 681-697. doi: 10.1128/mmbr 40.3.681-697.1976

Park, K.-P., Rosell, A., Foerch, C., Xing, C., Kim, W. J., Lee, S., et al. (2009). Plasma and brain matrix metalloproteinase- 9 after acute focal cerebral ischemia in rats. Stroke 40, 2836-2842. doi: 10.1161/STROKEAHA.109.554824

Paumen, M. B., Ishida, Y., Han, H., Muramatsu, M., Eguchi, Y., Tsujimoto, Y., et al. (1997). Direct Interaction of the Mitochondrial Membrane Protein Carnitine Palmitoyltransferase I with Bcl-2. Biochem. Biophys. Res. Commun. 231, 523-525. doi: 10.1006/bbrc.1997.6089

Phillips, J. B., Williams, A. J., Adams, J., Elliott, P. J., and Tortella, F. C. (2000). Proteasome inhibitor PS519 reduces infarction and attenuates leukocyte infiltration in a rat model of focal cerebral ischemia. Stroke 31, 1686-1693. doi: 10.1161/01.str.31.7.1686

Qosa, H., Miller, D. S., Pasinelli, P., and Trotti, D. (2015). Regulation of ABC efflux transporters at blood-brain barrier in health and neurological disorders. Brain Res. 1628, 298-316. doi: 10.1016/j.brainres.2015.07.005

Radu, M., and Chernoff, J. (2013). An in vivo assay to test blood vessel permeability. J. Vis. Exp. 2013:e50062. doi: 10.3791/50062

Rassow, J. (ed.) (2006). Biochemie: 50 Tabellen. Stuttgart: Thieme.

Rempe, R. G., Hartz, A. M. S., and Bauer, B. (2016). Matrix metalloproteinases in the brain and blood-brain barrier: Versatile breakers and makers. J. Cereb. Blood Flow Metab. Off. J. Int. Soc. Cereb. Blood Flow Metab. 36, 1481-1507. doi: 10.1177/0271678X16655551

Ridder, D. A., and Schwaninger, M. (2009). NF-kappaB signaling in cerebral ischemia. Neuroscience 158, 995-1006. doi: 10.1016/j.neuroscience.2008.07.007

Schildge, S., Bohrer, C., Beck, K., and Schachtrup, C. (2013). Isolation and culture of mouse cortical astrocytes. J. Vis. Exp. 2013:50079. doi: 10.3791/50079

Singh, N., Singh, H., Jagavelu, K., Wahajuddin, M., and Hanif, K. (2017). Fatty acid synthase modulates proliferation, metabolic functions and angiogenesis in hypoxic pulmonary artery endothelial cells. Eur. J. Pharmacol. 815, 462-469. doi: 10.1016/j.ejphar.2017.09.042

Song, J., Wu, C., Korpos, E., Zhang, X., Agrawal, S. M., Wang, Y., et al. (2015). Focal MMP-2 and MMP-9 activity at the blood-brain barrier promotes chemokineinduced leukocyte migration. Cell Rep. 10, 1040-1054. doi: 10.1016/j.celrep. 2015.01.037

Spudich, A., Kilic, E., Xing, H., Kilic, U., Rentsch, K. M., Wunderli-Allenspach, H., et al. (2006). Inhibition of multidrug resistance transporter-1 facilitates neuroprotective therapies after focal cerebral ischemia. Nat. Neurosci. 9, 487488. doi: $10.1038 / \mathrm{nn} 1676$

Suofu, Y., Clark, J. F., Broderick, J. P., Kurosawa, Y., Wagner, K. R., and Lu, A. (2012). Matrix metalloproteinase-2 or -9 deletions protect against hemorrhagic transformation during early stage of cerebral ischemia and reperfusion. Neuroscience 212, 180-189. doi: 10.1016/j.neuroscience.2012.03.036

Svensson, R. U., Parker, S. J., Eichner, L. J., Kolar, M. J., Wallace, M., Brun, S. N., et al. (2016). Inhibition of acetyl-CoA carboxylase suppresses fatty acid synthesis and tumor growth of non-small-cell lung cancer in preclinical models Nat. Med. 22, 1108-1119. doi: 10.1038/nm.4181

Takata, F., Dohgu, S., Yamauchi, A., Matsumoto, J., Machida, T., Fujishita, K., et al. (2013). In vitro blood-brain barrier models using brain capillary endothelial cells isolated from neonatal and adult rats retain age-related barrier properties. PLoS One 8:e55166. doi: 10.1371/journal.pone.0055166

Turner, R. J., and Sharp, F. R. (2016). Implications of MMP9 for Blood Brain Barrier Disruption and Hemorrhagic Transformation Following Ischemic Stroke. Front. Cell Neurosci. 10:56. doi: 10.3389/fncel.2016.00056

Watson, P. M. D., Paterson, J. C., Thom, G., Ginman, U., Lundquist, S., and Webster, C. I. (2013). Modelling the endothelial blood-CNS barriers: a method for the production of robust in vitro models of the rat blood-brain barrier and blood-spinal cord barrier. BMC Neurosci. 14:59. doi: 10.1186/1471-2202-14-59

Yang, C., and Candelario-Jalil, E. (2017). "Role of Matrix Metalloproteinases in Brain Edema," in Brain Edema, eds J. Badaut and N. Plesnila (Amsterdam: Elsevier), 199-215. doi: 10.1016/B978-0-12-803196-4.00011-4

Yang, S., Jin, H., and Zhao, Z. (2018). Paracellular tightness and the functional expression of efflux transporters P-gp and BCRP in bEnd3 cells. Neurol. Res. 40, 644-649. doi: 10.1080/01616412.2018.1460701

Yigitkanli, K., Pekcec, A., Karatas, H., Pallast, S., Mandeville, E., Joshi, N., et al. (2013). Inhibition of 12/15-lipoxygenase as therapeutic strategy to treat stroke. Ann. Neurol. 73, 129-135. doi: 10.1002/ana.23734

Ying, W., Wei, G., Wang, D., Wang, Q., Tang, X., Shi, J., et al. (2007). Intranasal administration with NAD+ profoundly decreases brain injury in a rat model of transient focal ischemia. Front. Biosci. J. Virtual Libr. 12:2728-2734. doi: $10.2741 / 2267$

Zaytseva, Y. Y., Elliott, V. A., Rychahou, P., Mustain, W. C., Kim, J. T., Valentino, J., et al. (2014). Cancer cell-associated fatty acid synthase activates endothelial cells and promotes angiogenesis in colorectal cancer. Carcinogenesis 35, 1341-1351. doi: $10.1093 /$ carcin/bgu042

Zhang, H. R., Peng, J. H., Zhu, G. Y., and Xu, R. X. (2015). Neuroprotective effects of Bcl-2 overexpression on nerve cells of rats with acute cerebral infarction. Genet. Mol. Res. GMR 14, 7696-7703. doi: 10.4238/2015.July.13.15

Zhang, J. W., and Gottschall, P. E. (1997). Zymographic measurement of gelatinase activity in brain tissue after detergent extraction and affinity-support purification. J. Neurosci. Methods 76, 15-20. doi: 10.1016/s0165-0270(97) 00065-4

Zhang, L., Graf, I., Kuang, Y., Zheng, X., Haupt, M., Majid, A., et al. (2021). Neural Progenitor Cell-Derived Extracellular Vesicles Enhance Blood-Brain Barrier Integrity by NF- $\kappa \mathrm{B}$ (Nuclear Factor- $\kappa \mathrm{B}$ )-Dependent Regulation of $\mathrm{ABCB}$ (ATP-Binding Cassette Transporter B1) in Stroke Mice. Arterioscler. Thromb. Vasc. Biol. 41, 1127-1145. doi: 10.1161/ATVBAHA.120.315031

Zhang, L., Zhang, Z. G., Liu, X., Hozeska, A., Stagliano, N., Riordan, W., et al. (2006). Treatment of embolic stroke in rats with bortezomib and recombinant human tissue plasminogen activator. Thromb. Haemost. 95, 166-173. doi: 10. 1160/th05-07-0477

Zhang, Y., Fu, R., Liu, Y., Li, J., Zhang, H., Hu, X., et al. (2016). Dephosphorylation and mitochondrial translocation of cofilin sensitizes human leukemia cells to cerulenin-induced apoptosis via the ROCK1/Akt/JNK signaling pathway. Oncotarget 7:7994. doi: 10.18632/oncotarget.7994

Zhang, Y., Xiong, M., Yan, R.-Q., and Sun, F.-Y. (2010). Mutant ubiquitin-mediated beta-secretase stability via activation of caspase-3 is related to beta-amyloid accumulation in ischemic striatum in rats. J. Cereb. Blood Flow Metab. Off. J. Int. Soc. Cereb. Blood Flow Metab. 30, 566-575. doi: 10.1038/jcbfm.2009.228

Zhao, H., Yenari, M. A., Cheng, D., Sapolsky, R. M., and Steinberg, G. K. (2003). $\mathrm{Bcl}-2$ overexpression protects against neuron loss within the ischemic margin following experimental stroke and inhibits cytochrome $c$ translocation and caspase- 3 activity: Bcl-2 protects neurons in the infarct margin. J. Neurochem. 85, 1026-1036. doi: 10.1046/j.1471-4159.2003.01756.x

Zhao, W., Kridel, S., Thorburn, A., Kooshki, M., Little, J., Hebbar, S., et al. (2006) Fatty acid synthase: a novel target for antiglioma therapy. Br. J. Cancer 95, 869-878. doi: 10.1038/sj.bjc.6603350

Conflict of Interest: The authors declare that the research was conducted in the absence of any commercial or financial relationships that could be construed as a potential conflict of interest.

Publisher's Note: All claims expressed in this article are solely those of the authors and do not necessarily represent those of their affiliated organizations, or those of the publisher, the editors and the reviewers. Any product that may be evaluated in this article, or claim that may be made by its manufacturer, is not guaranteed or endorsed by the publisher.

Copyright (C) 2021 Janssen, Ai, Zheng, Wei, Caglayan, Kilic, Wang, Hermann, Venkataramani, Bähr and Doeppner. This is an open-access article distributed under the terms of the Creative Commons Attribution License (CC BY). The use, distribution or reproduction in other forums is permitted, provided the original author(s) and the copyright owner(s) are credited and that the original publication in this journal is cited, in accordance with accepted academic practice. No use, distribution or reproduction is permitted which does not comply with these terms. 